\title{
NF- $\kappa$ B and Nrf2 signaling pathways contribute to wogonin-mediated inhibition of inflammation-associated colorectal carcinogenesis
}

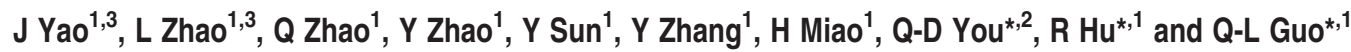

The transcriptional factors nuclear factor- $\kappa \mathrm{B}$ (NF- $\kappa \mathrm{B}$ ) and NF-E2-related factor 2 (Nrf2) have been recently reported to have critical roles in protecting various tissues against inflammation and colitis-associated colorectal cancer (aberrant crypt foci). Our previous studies showed that wogonin (5,7-dihydroxy-8-methoxyflavone) possessed anti-neoplastic and anti-inflammatory activities. The present study extended these important earlier findings by exploring the effect of wogonin on the initiation and development of colitis-associated cancer. Wogonin lowered tumor incidence and inhibited the development of colorectal adenomas in azoxymethane- or dextran sulfate sodium-induced mice. We found that wogonin significantly decreased the secretion and expression of IL- 6 and IL- $1 \beta$, reduced cell proliferation and nuclear expression of NF- $\kappa$ B in adenomas and surrounding tissues and promoted Nrf2 nuclear translocation in surrounding tissues, although overexpressed Nrf2 in tumor tissues was independent of wogonin administration. Furthermore, wogonin inhibited the interaction between human monocytic THP-1 cells and human colon cancer HCT116 cells, and significantly downregulated lipopolysaccharide-induced secretion of prototypical pro-inflammatory cytokines IL- 6 and IL-1 $\beta$ in THP-1 cells. Further mechanism research revealed that wogonin inhibited the nuclear translocation of NF- $\kappa B$ and phosphorylation of $I \kappa B$ and IKK $\alpha / \beta$, and promoted Nrf2 signaling pathway in HCT116 cells and THP-1 cells. Taken together, the present results indicated that wogonin effectively suppressed inflammation-associated colon carcinogenesis and cancer development, suggesting its potential as a chemopreventive agent against colitis-associated colon cancer.

Cell Death and Disease (2014) 5, e1283; doi:10.1038/cddis.2014.221; published online 5 June 2014

Subject Category: Cancer

Colorectal cancer (CRC) is the third most commonly diagnosed cancer and accounts for $\sim 10 \%$ of all cancerrelated deaths. ${ }^{1}$ Patients with inflammatory bowel disease (IBD) are at a significantly increased risk of developing CRC. Therefore, new strategies are still required for achieving effective treatment, which might ultimately aid the clinical therapy for IBD patients. Administration of a single injection of the classic colon carcinogen azoxymethane (AOM) to mice before pro-inflammatory reagent dextran sulfate sodium (DSS) has been used to induce colitis-associated cancer (CAC), which has extensively been used for investigating new chemopreventive agents against colitis-associated colon cancer. $^{2}$ In addition, DSS dissolved in drinking water is directly toxic to gut epithelial cells of the basal crypts and affects the integrity of the mucosal barrier, resulting in severe colitis characterized by bloody diarrhea, ${ }^{2}$ and the powerful tumor-promoting effect of DSS is related to its induction of inflammatory oxidative/nitrosative stress. ${ }^{3}$

Inflammatory cytokines have critical roles in IBD-related intestinal cancer. ${ }^{4} \mathrm{IL}-6$ and IL-1 $\beta$ are pleiotropic pro-inflammatory cytokines that have profound effects on several diseases including cancers. ${ }^{5,6}$ Accordingly, their upstream nuclear factor $-\kappa \mathrm{B}(\mathrm{NF}-\kappa \mathrm{B})$ signaling pathway is crucial both in tumor cells and inflammatory cells. ${ }^{7}$ Owing to the target genes that include those encoding pro-inflammatory cytokines and chemokines, it has been proposed that NF- $\kappa \mathrm{B}$ activation might link inflammation to tumor initial and promotion. 7,8

The Kelch-like ECH-associated protein 1 (Keap1)-NF-E2related factor 2 (Nrf2) system regulates the expression of a battery of cytoprotective genes in response to electrophilic and oxidative stresses. $^{9}$ Nrf2, a key transcription factor, regulates the basal and inducible expression of numerous

\footnotetext{
${ }^{1}$ State Key Laboratory of Natural Medicines, Jiangsu Key Laboratory of Carcinogenesis and Intervention, China Pharmaceutical University, 24 Tongjiaxiang, Nanjing 210009, China and 2Jiangsu Center for Pharmacodynamics Research and Evaluation, China Pharmaceutical University, Nanjing 210009, China

*Corresponding authors: Q-D You, Jiangsu Center for Pharmacodynamics Research and Evaluation, China Pharmaceutical University, 24 Tongjiaxiang, Nanjing 210009 , China. Tel/Fax: + 8625 83271206; E-mail: youqd@163.com

or R Hu, Jiangsu Key Laboratory of Carcinogenesis and Intervention, China Pharmaceutical University, 24 Tongjiaxiang, Nanjing 210009, China. Tel/Fax: + 8625 83271055; E-mail: ronghu@cpu.edu.cn

or Q-L Guo, State Key Laboratory of Natural Medicines, Jiangsu Key Laboratory of Carcinogenesis and Intervention, China Pharmaceutical University, 24 Tongjiaxiang, Nanjing 210009, China. Tel/Fax: + 8625 83271055; E-mail: anticancer_drug @163.com

${ }^{3}$ These authors contributed equally to this work.

Keywords: wogonin; AOM/DSS mouse model; colitis-associated cancer; NF- $\kappa \mathrm{B}$; Nrf2

Abbreviation: CRC, colorectal cancer; CAC, colitis-associated cancer; IBD, inflammatory bowel disease; ROS, reactive oxygen species; LPS, lipopolysaccharide; MTT, 3-(4,5-dimethylthiazol-2-yl)-2,5-di-phenyltetrazolium bromide; DMSO, dimethyl sulfoxide; NF- $\kappa$ B, nuclear factor- $\kappa$ B; Nrf2, NF-E2-related factor 2; PI3K, phosphatidylinositol 3-kinase; EMSA, electrophoretic mobility shift assay; PCNA, proliferating cell nuclear antigen; AOM, azoxymethane; DSS, dextran sulfate sodium Received 15.12.13; revised 12.4.14; accepted 15.4.14; Edited by A Stephanou
} 
detoxifying and antioxidant genes (for example, glutathione S-transferases and $\mathrm{NAD}(\mathrm{P}) \mathrm{H}$ : quinone oxidoreductase (NQO1)), thiol molecules and their regenerating enzymes (for example, thioredoxin and glutamate cysteine ligase), stress-response proteins (for example, heme oxygenase-1 $(\mathrm{HO}-1)$ ), and direct reactive oxygen species (ROS)-removing enzymes (for example, glutathione peroxidase), through consensus cis-elements called antioxidant-response elements (AREs). ${ }^{10}$ Keap1 is a member of the large BTB-Kelch protein family that functions as a substrate adaptor protein for a Cul3-Rbx 1 E $3^{1}$ ubiquitin ligase complex. Under conditions of homeostatic cell growth, the cytoplasmic protein Keap1 interacts with Nrf2, and represses its function. ${ }^{11}$ However, following exposure to a wide variety of chemical inducers of Nrf2-dependent transcription, ubiquitination of Keap1 is markedly increased and Keap1-dependent ubiquitination of Nrf2 is blocked, occurs in parallel with inhibition of Keap1dependent ubiquitination of Nrf2, and results in decreased nuclear translocation of Nrf2 and activated Nrf2-dependent genes. ${ }^{12}$ Furthermore, extensive studies have suggested that the Nrf2-Keap1 system contributes to protection against various pathologies, including carcinogenesis, liver toxicity, respiratory distress and inflammation. ${ }^{13,14}$

Wogonin (5,7-dihydroxy-8-methoxyflavone), a flavonoid derived from the root of Scutellaria baicalensis Georgi, is traditionally used in the treatment of inflammatory diseases. Its anti-inflammatory effect has been attributed to the suppression of NO production via downregulation of several inflammation-associated mediators such as inducible NO synthase and cyclooxygenases ${ }^{15,16}$ and inhibited the expression and activation of NF- $\kappa \mathrm{B}$ in vivo and in vitro. ${ }^{17}$ Moreover, there is a staggering amount of literature that Nrf2 contributes to the protective effects of flavonoids against cellular and tissue injury, such as luteolin, ${ }^{18}$ fisetin ${ }^{19}$ and genistein. ${ }^{20}$ But whether wogonin inhibits NF- $\kappa \mathrm{B}$ activation and induces the activation of Nrf2 expression during the malignant transformation of inflammation is needed to be investigated. Therefore, the present study was undertaken to examine the effect of wogonin on colitis-associated colorectal carcinogenesis in AOM/DSS model and investigate its mechanisms.

\section{Results}

In vivo effects of wogonin on inflammation-associated CRC. To investigate the effects of wogonin on CAC development, we established the AOM/DSS model in C57BL/6 mice (Figure 1a). Kaplan-Meier survival curves showed that wogonin treatment significantly increased the survival of AOM/DSS-treated mice during the experiment (Figure 1b). The body weights of mice were monitored throughout the study, and the results showed that animals lost weight after each exposure to DSS and wogonin regained the body weight of AOM/DSS mice (Figure 1c). Neither changes in indexes of hematology nor noticeable signs of toxicity in mice were observed in all groups up to 105 days (Tables 1 and 2 ).

Assessment of tumor number, tumor size and tumor load (the sum of tumor diameters per colon) at the end of the animal experiment showed that wogonin reduced tumor number, tumor size and average tumor load in AOM/DSS model (Figures 1d-f). In addition, a lower frequency of largesized adenomas was observed in wogonin-treated group than in AOM/DSS group (Figure 1g). As shown in Figure 1h, colons were shorter in AOM/DSS group than in the wogonintreatment groups at day 105 , but we found no significant difference between these two groups.

Histological examination of colonic sections was performed to assess intestinal inflammatory status. As shown in Figure 1i, the results of hematoxylin and eosin (H\&E) staining showed that samples at day 29 had slight necrosis of the mucosa epithelium tissues, and mild hyperemia and edema of the lamina propria; samples at day 48 had mucosa lamina propria with edema, accompanied by degeneration and necrosis of crypt cells and an amount of infiltrative inflammatory cells; samples at day 68 presented severe mucosal necrosis and a large number of inflammatory cell infiltration; samples at day 105 had a large adenocarcinoma inside lumen and it exhibited that several abnormal cells exhibited cylindrical shape, large nuclei, increasing nuclear/cytoplasmic $(\mathrm{N} / \mathrm{C})$ ratio and cellular cleavage, and the glands have abnormal sizes and shapes. Conversely, wogonin relieved these symptoms significantly in different periods. The abnormal presentation that tumor tissues were not adherent to intestinal mucosa resulted from operational problems.

Taken together, these results indicated that wogonin inhibited inflammation-related carcinogenesis and tumor development in AOM/DSS mouse model.

Wogonin inhibits cell proliferation and production of pro-inflammatory mediators and regulates expression of NF- $\boldsymbol{\kappa}$ B and Nrf2 in vivo. Uncontrolled colonocyte proliferation is the common event that occurs at the cellular level during colon carcinogenesis. Accordingly, cellular proliferation in surrounding and tumor tissues was evaluated using BrdU and proliferating cell nuclear antigen (PCNA) staining (Figure 2a). Moreover, Image pro plus software (Media Cybernetics, Silver Spring, MD, USA) was used to analyze the positive cells and we added the integrated optical density (IOD) of BrdU- and PCNA-positive cells as shown in Figure $2 b$. These results showed a significantly lower number of BrdU- and PCNA-labeled cells in wogonin-treated mice than in those of AOM/DSS-treated mice. These results indicated that wogonin suppressed cellular proliferation in surrounding and tumor tissues.

As the important role of cytokines in the development of CAC, we next detected the expression of IL- 6 and IL- $1 \beta$ in CAC mice using immunohistochemical staining. IL-6 and IL- $1 \beta$ were expressed at relatively high levels in mouse model; however, wogonin effectively suppressed the expression of IL-6 and IL-1 $\beta$ (Figures $2 \mathrm{c}$ and d). In addition, we tested the effect of wogonin on the mRNA levels of IL- 6 and IL- $1 \beta$ in surrouding tissues of AOM/DSS-treated mice. As shown in Figure 2e, wogonin significantly decreased the mRNA levels of IL-6 and IL-1 $\beta$.

In addition, results of immunohistochemical staining and western blots showed that wogonin reduced nuclear NF- $\kappa$ B p65 protein expression in surrounding and tissues of AOM/DSStreated mice (Figures $2 \mathrm{f}-\mathrm{i}$ ). Overexpressed Nrf2 translocated into nuclei in tumor tissues of AOM/DSS-treated mice at day 105 , and it was not obvious change administrated with wogonin. 
a

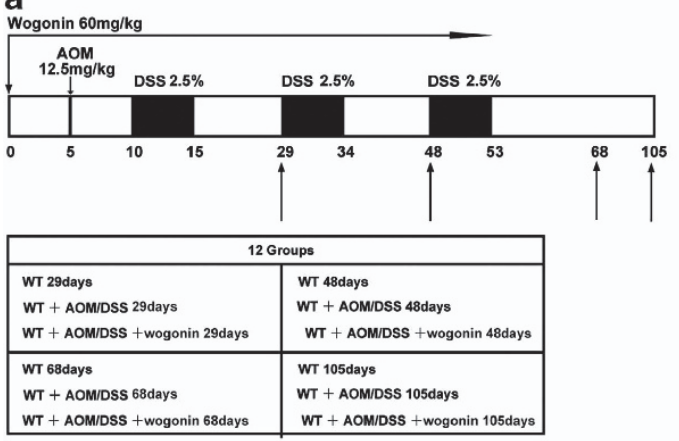

b

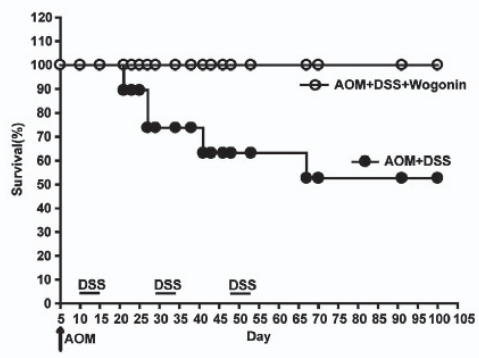

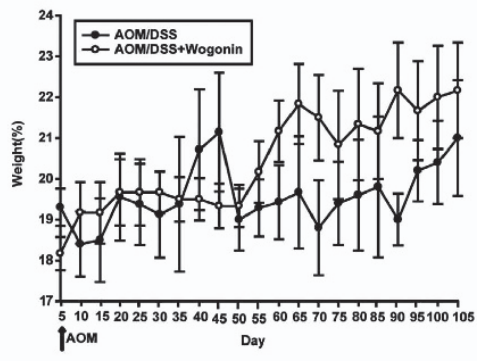
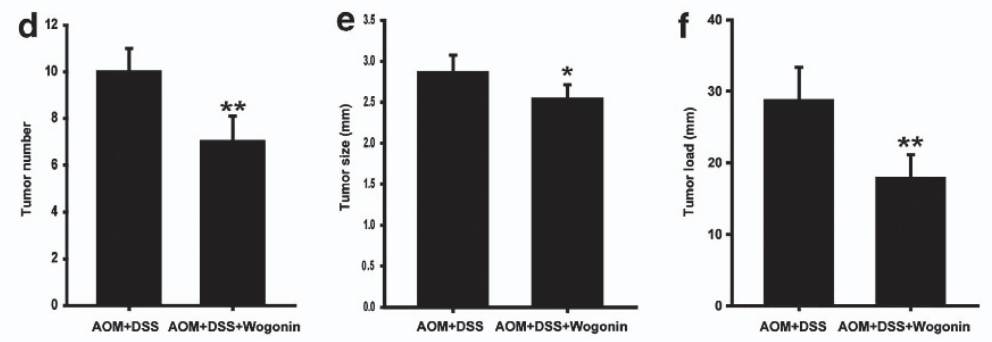

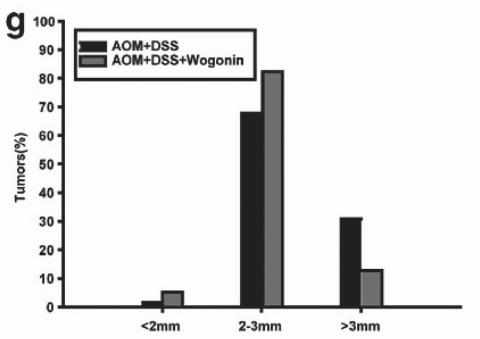

h
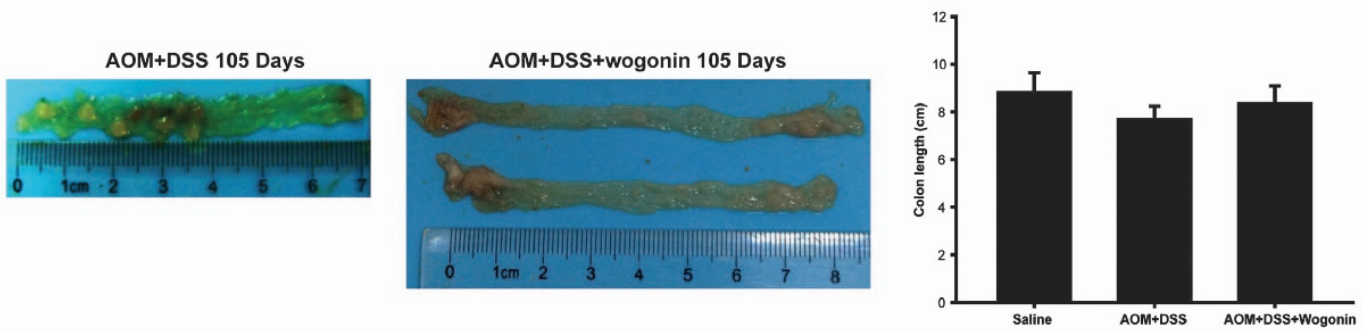

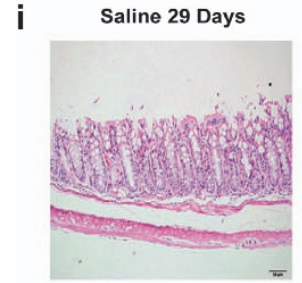

Saline 48 Days

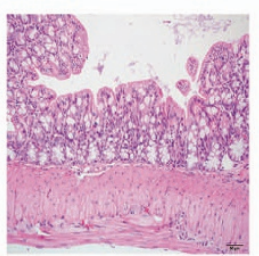

AOM+DSS 29 Days AOM+DSS+wogonin 29 Days
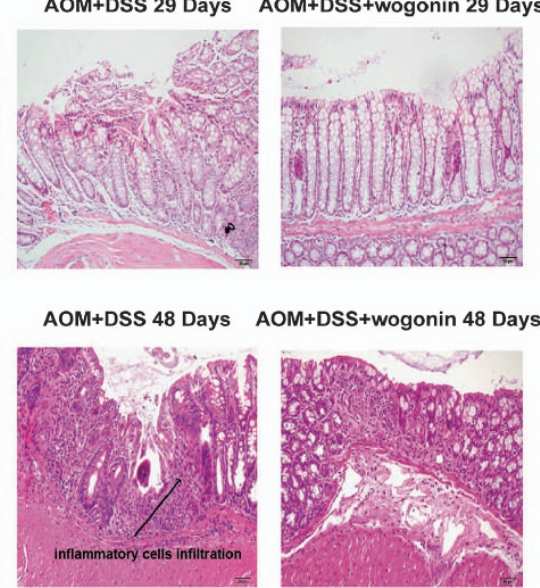

Saline 68 Days
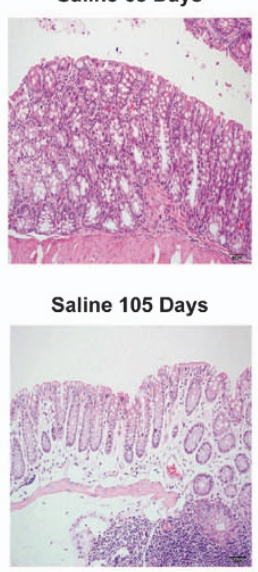

AOM+DSS 68 Days AOM+DSS+wogonin 68 Days

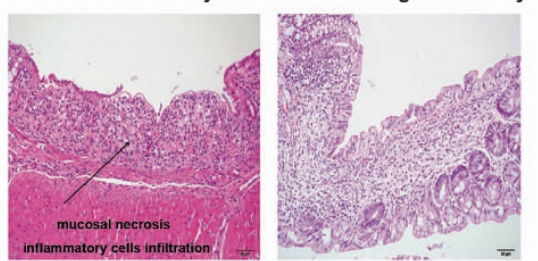

AOM+DSS 105 Days AOM+DSS+wogonin 105 Days
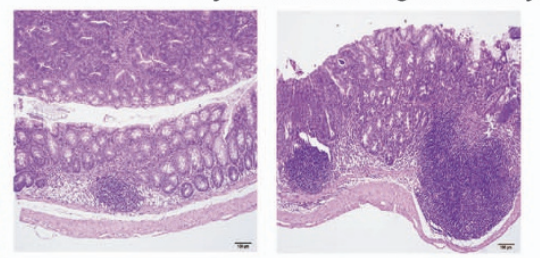

Figure 1 Wogonin reduced the incidence and development of CAC. C57BL/6 mice were subjected to an AOM-based CAC induction protocol using three cycles of $2.5 \%$ DSS in drinking water. (a) Diagram shows the experimental course of AOM/DSS mouse model. (b) Kaplan-Meier survival curves show the effect of wogonin on the survival of AOM/DSS-treated mice. (c) Body weights of the AOM/DSS group and AOM/DSS + wogonin group were measured. (d) Tumor numbers were counted on day 106. Data represent average tumor numbers \pm S.D. $(n=6) .{ }^{* *} P<0.01$ compared with AOM/DSS group. (e) Tumor sizes were determined using Spot software for microscopic tumors or a caliper for macroscopic tumors. Average tumor size \pm S.D. is shown; ${ }^{*} P<0.05,{ }^{* *} P<0.01$ compared with AOM/DSS group. (f) Average tumor load was determined. Results are averages \pm S.D. $(n=6)$. ${ }^{\star \star} P<0.01$ compared with AOM/DSS group. (g) Histogram showing the size distribution of tumors. (h) Representative images of colons removed from mice in AOM/DSS group and AOM/DSS + wogonin group at day 105 and data statistics of the colon length. (i) H\&E stains of serial sections of colons. The arrows showed the possible presence of adenocarcinoma tissues

However, a significantly increased Nrf2 translocation into the nucleus in surrounding tissues was observed in the wogonintreated group at days 29, 48 and 68 . The above phenomenon indicated that wogonin inhibited NF- $\kappa \mathrm{B}$ and promoted Nrf2 activation to decrease the inflammation-induced injury, and prevented the incidence and the development of CAC. 
Wogonin inhibits the growth of HCT116 cells exposed to the supernatant of lipopolysaccharide-stimulated THP-1 cells. On the basis of the results in Figure 2a, we proposed that wogonin inhibited inflammation-induced proliferation of cancer cells. Then, we used a culture system, which exposed HCT116 cells with the conditional media from lipopolysaccharide (LPS)-stimulated THP-1 cells, to detect the interaction between inflammation and tumor progression and verify this hypothesis.

Recent studies indicated that aberrant bacterial LPSmediated inflammatory mediators and signaling pathways in gut mucosa may be involved in the pathogenesis of inflammation-related cancer. ${ }^{21-23}$ Therefore, we used LPS as a stimulator to mimic the inflammatory environment for the later experiments.

We found that the conditional media from LPS-induced THP-1 cells promoted the growth of HCT116 cells compared with HCT116 monolayer alone. However, wogonin markedly inhibited the proliferation of HCT116 cells supported by the conditional medium as shown in Figure $3 a$. Western blot analysis showed that PCNA expression was upregulated in HCT116 cells supported by LPS-stimulated THP-1 cells and this upregulation was reversed by wogonin

Table 1 Effect of wogonin on indexes of hemotology in different groups at day 106

\begin{tabular}{lccc}
\hline Treatments & \multicolumn{3}{c}{ Parameters } \\
\cline { 2 - 4 } & WBC & $\begin{array}{c}\text { Neutrophil } \\
\text { ratio (\%) }\end{array}$ & $\begin{array}{c}\text { Lymphocyte } \\
\text { ratio (\%) }\end{array}$ \\
\hline Saline & $5.02 \pm 0.36$ & $12.05 \pm 1.01$ & $83.25 \pm 3.41$ \\
AOM/DSS & $4.94 \pm 0.77$ & $12.84 \pm 1.89$ & $81.75 \pm 2.47$ \\
AOM/DSS + wogonin & $5.48 \pm 1.41$ & $12.21 \pm 1.34$ & $88.25 \pm 2.32$ \\
\hline
\end{tabular}

Abbreviation: WBC, white blood cells

Each data point represents the mean \pm S.D. of five animals for each group

Table 2 Effect of wogonin on weights of main organs in different groups at day 106

\begin{tabular}{lccc}
\hline \multirow{2}{*}{ Treatments } & \multicolumn{3}{c}{ Weights $\mathbf{( g )}$} \\
\cline { 2 - 4 } & Liver & Spleen & Lung \\
\hline Saline & $1.094 \pm 0.098$ & $0.092 \pm 0.012$ & $0.133 \pm 0.009$ \\
AOM/DSS & $1.132 \pm 0.111$ & $0.090 \pm 0.012$ & $0.177 \pm 0.011$ \\
AOM/DSS + wogonin & $1.116 \pm 0.231$ & $0.105 \pm 0.002$ & $0.151 \pm 0.052$
\end{tabular}

Each data point represents the mean \pm S.D. of five animals for each group
(Figure 3b). Ki67 assay also showed that wogonin inhibited the proliferation of HCT116 cells in the conditional culture system (the ratio of HCT116 cells to THP-1 cells was $1: 10)$ (Figure 3c). These findings suggested that wogonin suppressed the induction of THP-1 cells on the proliferation of HCT116 cells.

Wogonin inhibits LPS-induced production of pro-inflammatory cytokines in THP-1 cells. Among the molecules involved in inflammation-related cancer, IL-1 $\beta$ and IL-6 were identified as the key endogenous (intrinsic) factors. ${ }^{6,24}$ In the above results, we found that wogonin inhibited the secretion and expression of IL-6 and IL- $1 \beta$ in vivo. Next, we detected the effect of wogonin on the production of these two cytokines in vitro. As shown in Figures $3 \mathrm{~d}$ and e, LPS treatment significantly increased IL- 6 and IL-1 $\beta$ secretion in THP-1 cells, and the secretion was inhibited by wogonin in a concentrationdependent manner. Furthermore, IL- 6 and IL- $1 \beta$ levels were undetectable in the culture media of LPS-stimulated HCT116 cells (data not shown). The inhibition of wogonin on the production of IL- 6 and IL- $1 \beta$ in THP- 1 cells was confirmed by quantifying mRNA expression (Figure 3f). These results indicated that wogonin inhibited the expression of IL- 6 and $\mathrm{IL}-1 \beta$ at the transcriptional level in LPS-stimulated THP-1 cells.

Wogonin downregulates LPS-induced NF- $\kappa$ B pathway in THP-1 cells. It is reported that NF- $\kappa \mathrm{B}$, partially induced by LPS, supervises the transformation of non-resolving inflammation. ${ }^{25}$ Therefore, the effect of wogonin on the activation of NF- $\kappa$ B pathway in THP-1 cells was detected in the next experiments. Moreover, we found that wogonin significantly inhibited LPS-induced NF- $\kappa$ B nuclear expression in THP-1 cells (Figure $3 \mathrm{~g}$ ). Stimulation with LPS in THP-1 cells for $60 \mathrm{~min}$ induced $\mathrm{I} \kappa \mathrm{B}$ phosphorylation, and this induction was significantly inhibited by wogonin; however, wogonin had no effects on $I_{\kappa} B$ protein levels (Figure $3 \mathrm{~h}$ ). In addition, wogonin significantly suppressed LPS-induced phosphorylation of IKK $\alpha / \beta$ (Figure 3i). These findings suggested that wogonin suppressed NF- $\kappa$ B activation by inhibiting phosphorylation of $\mathrm{IKK}$ and $\mathrm{I} \kappa \mathrm{B}$.

On the basis of the results above, we proposed that wogonin exerted its anti-inflammatory effect by decreasing the expression and activity of NF- $\kappa$ B in vitro. NF- $\kappa$ B plasmid was applied as a tool to examine this hypothesis. A decrease in the LPS-induced secretion of IL- 6 and IL- $1 \beta$ in THP- 1 cells after administrated with wogonin was found, whereas the inhibition was reversed in the presence of NF- $\kappa$ B plasmid transfection (Figure 3j).

\footnotetext{
Figure 2 Wogonin inhibited cellular proliferation, changed the inflammatory microenvironment and regulated the expression of NF- $\kappa$ B and Nrf2 in vivo. (a) The expression of BrdU and PCNA in surrounding and tumor tissues of AOM/DSS-treated mice was examined by immunohistochemistry. (b) Image pro plus software was used to quantify the IHC images. IOD of BrdU- and PCNA-positive cells was shown. All data are expressed as the mean \pm S.D., ${ }^{*} P<0.05,{ }^{* \star} P<0.01$ compared with saline group; ${ }^{\#} P<0.05$, $\# \#<0.01$ compared with AOM/DSS group. (c) The expression of IL-6 and IL-1 $\beta$ in surrounding tissues of AOM/DSS-treated mice was performed by immunohistochemistry. (d) IOD of IL-6- and IL-1 $\beta$-positive cells was shown. All data are expressed as the mean \pm S.D., ${ }^{*} P<0.05,{ }^{\star \star} P<0.01$ compared with saline group; ${ }^{\#} P<0.05$, ${ }^{\# \#} P<0.01$ compared with AOM/DSS group. (e) The mRNA levels of IL- 6 and IL-1 $\beta$ were measured by real-time RT-PCR, with the use of gene-specific TaqMan primers and a universal PCR master mixture. All data are expressed as the mean \pm S.D., ${ }^{*} P<0.05$, ${ }^{\star \star} P<0.01$ compared with AOM/DSS group. (f) Immunohistochemistry of NF- $\kappa$ B p65 and Nrf2 in surrounding and tumor tissues. (g) IOD of NF- $\kappa$ B p65- and Nrf2-positive cells was shown. All data are expressed as the mean \pm S.D., ${ }^{*} P<0.05$, ${ }^{* *} P<0.01$ compared with saline group; ${ }^{\#} P<0.05$, ${ }^{\#} P<0.01$ compared with AOM/DSS group. (h) NF- $\kappa B$ p 65 and Nrf2 nuclear translocations were measured at different time points by western blotting. (i) The relative expression of $\mathrm{NF}-\kappa \mathrm{B}$ p65 and Nrf2 in nuclear and cytosol fraction was represented by densitometric analysis. The results are representative of three independent experiments and expressed as means \pm S.D., ${ }^{*} P<0.05$, ${ }^{\star \star} P<0.01$ compared with saline group; ${ }^{\#} P<0.05$, ${ }^{\# \#} P<0.01$ compared with AOM/DSS group
} 

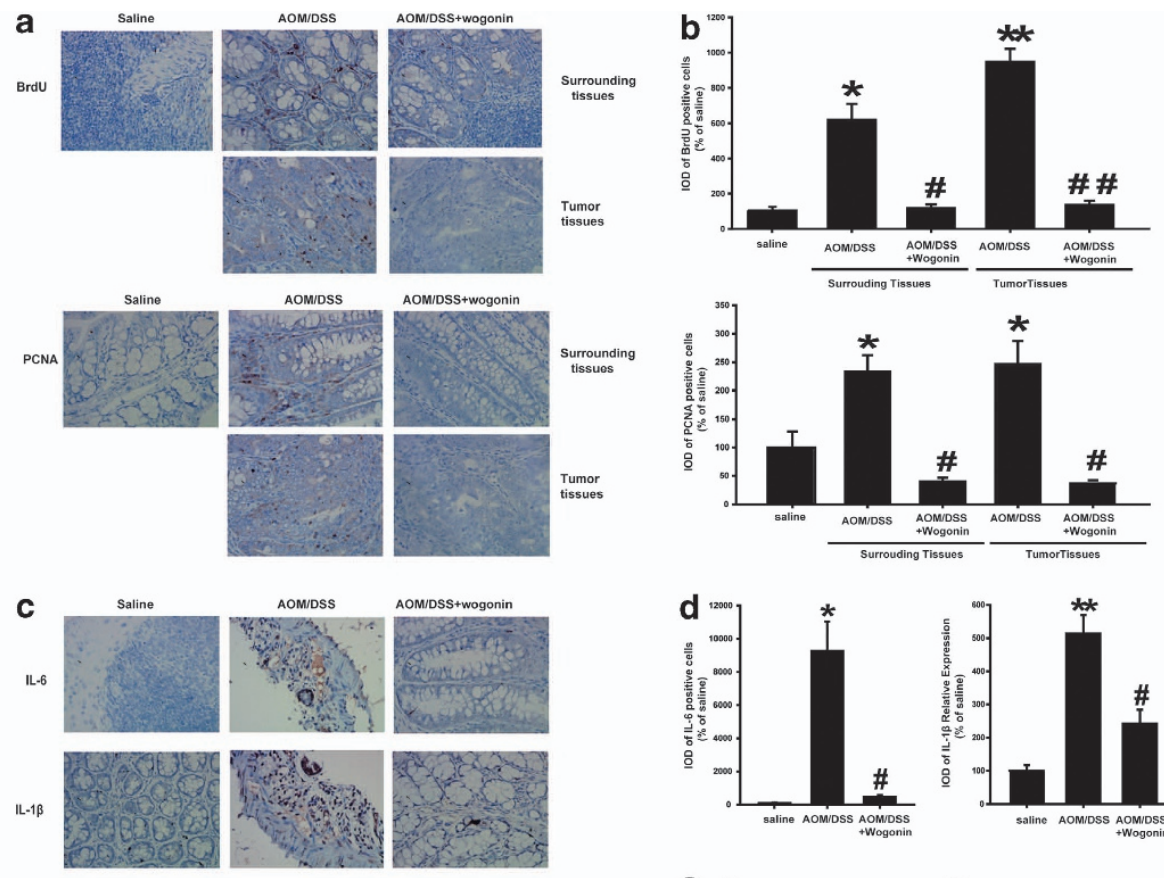

f
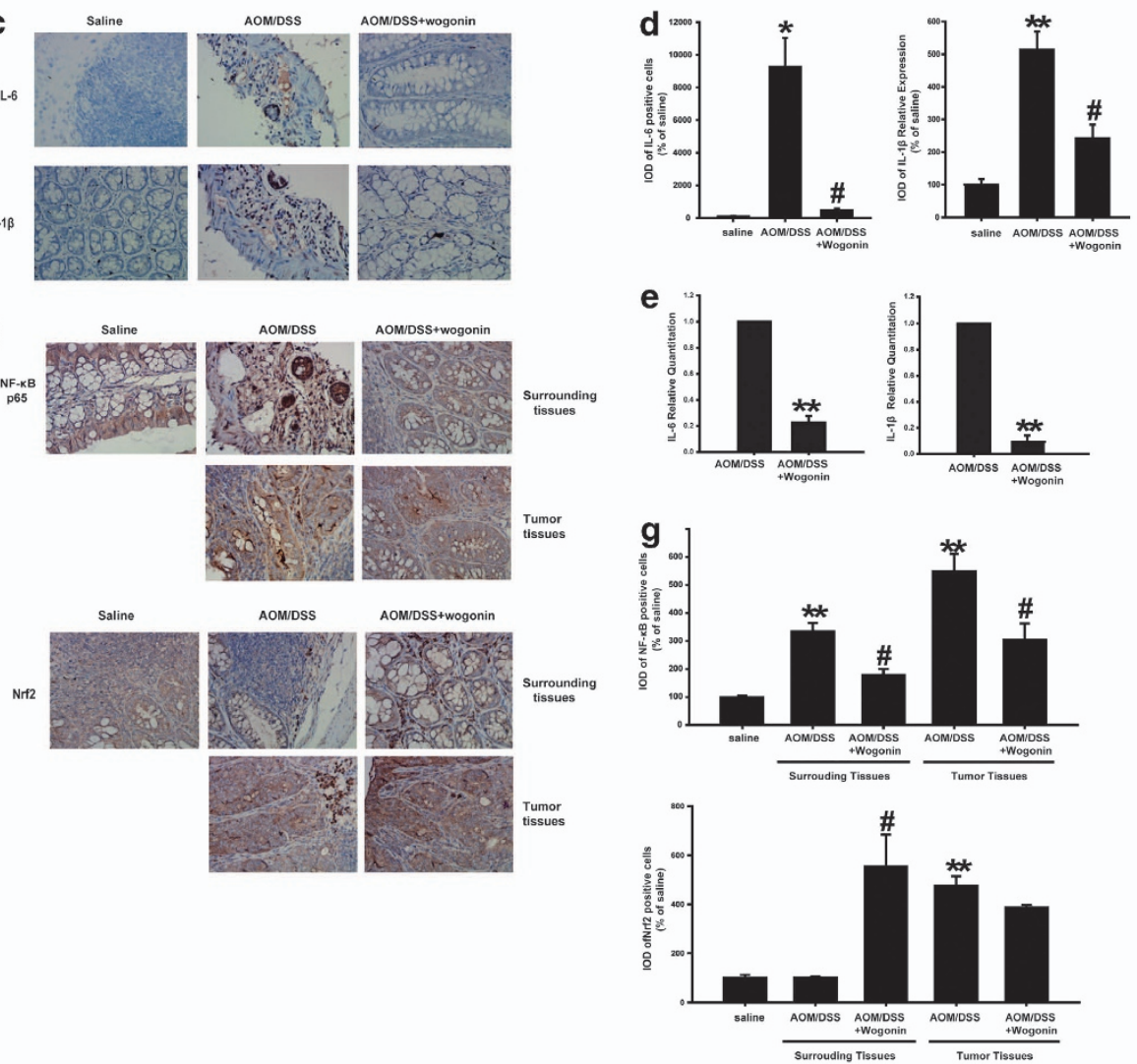

h
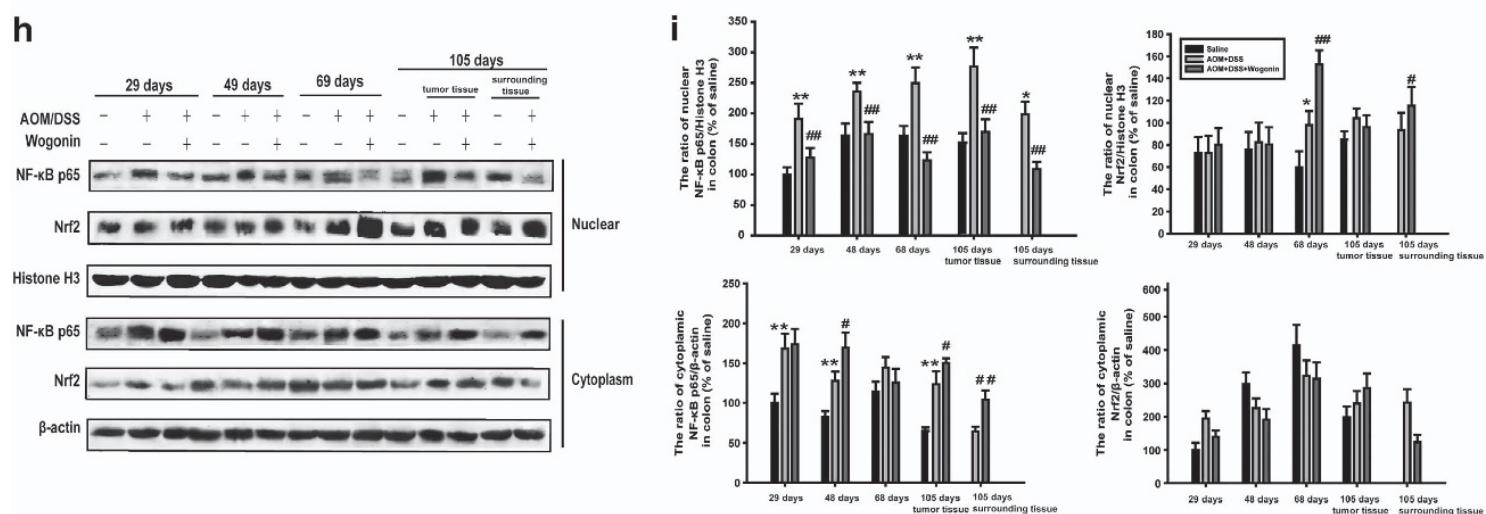
a

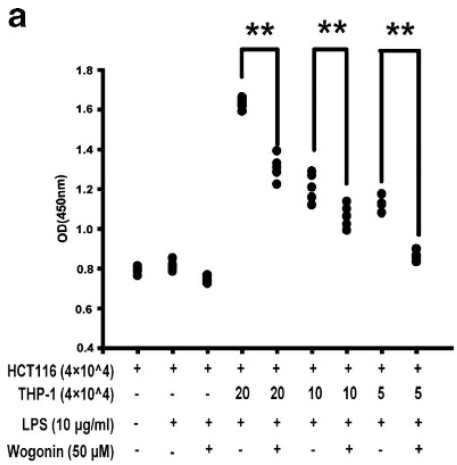

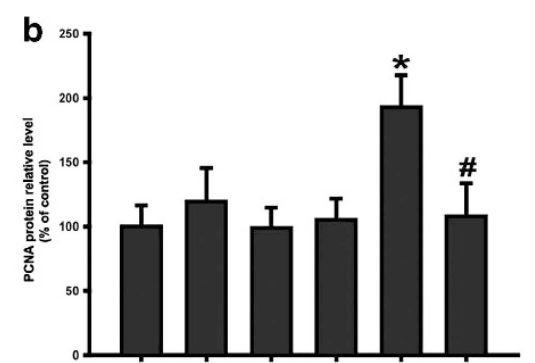

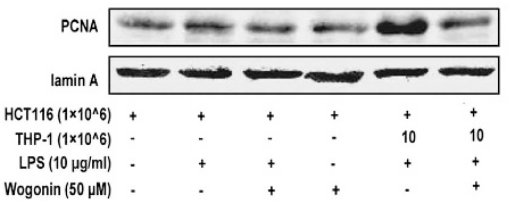

d

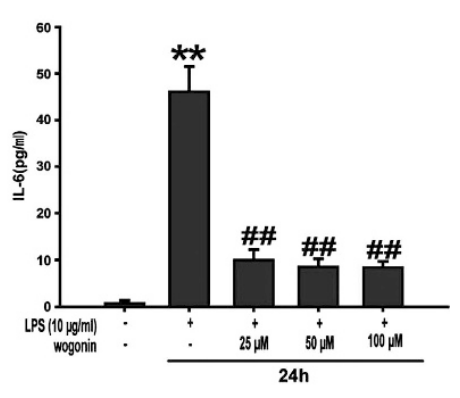

C

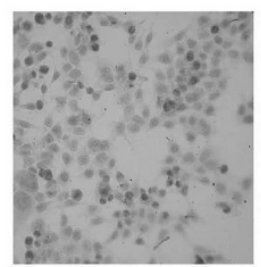

Con

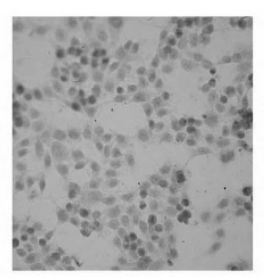

LPS

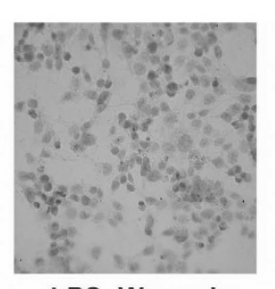

LPS+Wogonin

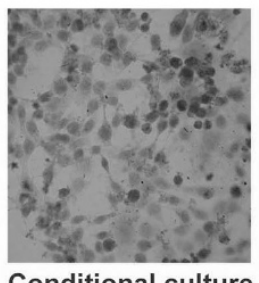

Conditional culture

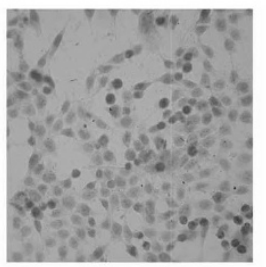

Conditional culture
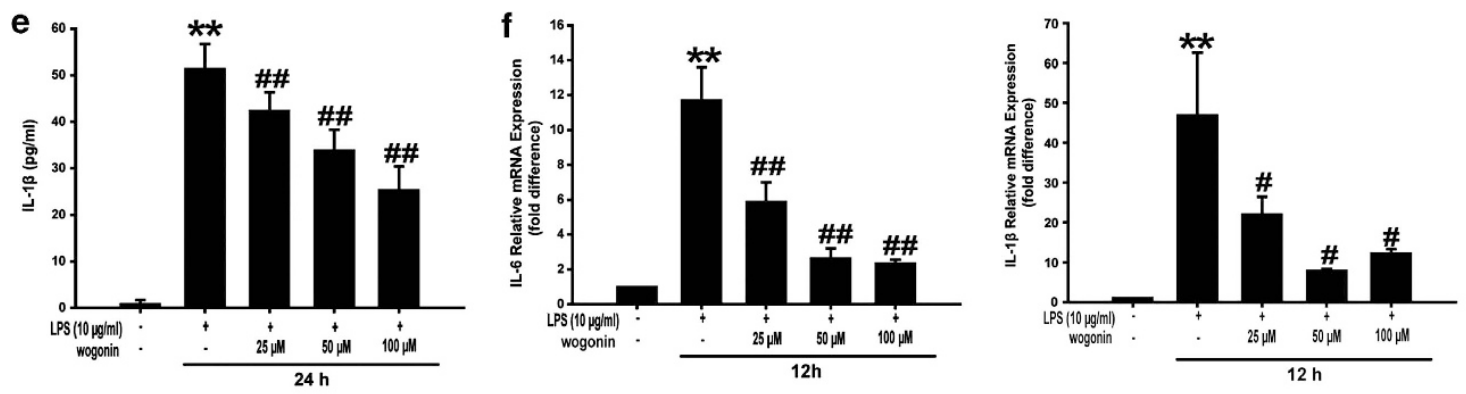

g
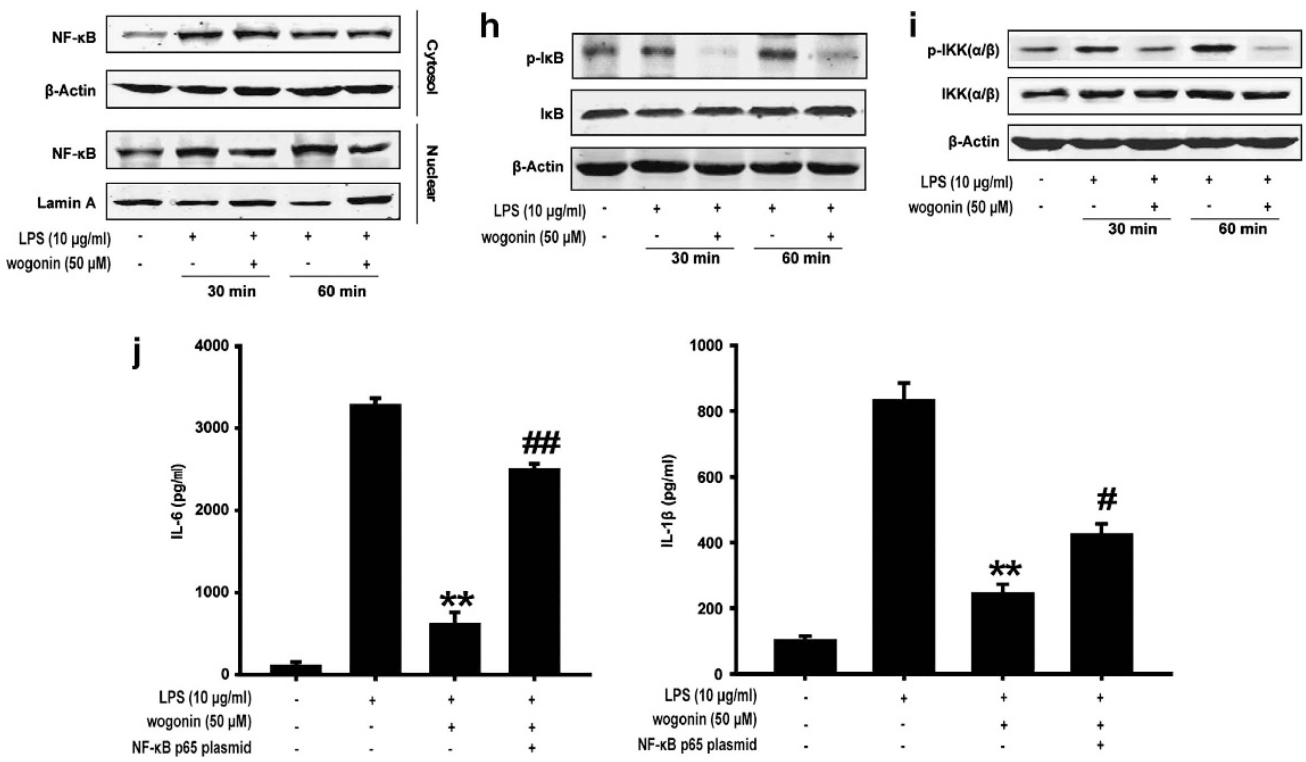
Wogonin inhibits LPS-induced NF- $\kappa$ B pathway and upstream MAPK-PI3K-Akt signaling pathway in HCT116 cells. NF- $\kappa$ B regulates the expression of multiple inflammation-associated proliferational genes and dysregulation of $\mathrm{NF}-\kappa \mathrm{B}$ pathway is crucial in cancer development. ${ }^{26}$ Therefore, we next detected the effect of wogonin on LPS-induced $\mathrm{NF}-\kappa \mathrm{B}$ activation in HCT116 cells. Wogonin inhibited nuclear translocation of $\mathrm{NF}-\kappa \mathrm{B}$ at $60 \mathrm{~min}$ showed by immunofluorescence confocal microscopy, whereas there was no obvious change at $30 \mathrm{~min}$ (Figure $4 \mathrm{a}$ ). The percent of NF- $\kappa$ B-positive cells was shown as a histograph in Figure 4b. Western blot analysis further confirmed that the LPS-induced $\mathrm{NF}-\kappa \mathrm{B}$ nuclear translocation was suppressed by wogonin at $60 \mathrm{~min}$ (Figure 4c). Wogonin significantly inhibited phosphorylation of $\mathrm{I} \kappa \mathrm{B}$ and $\mathrm{IKK} \alpha / \beta$ (Figures $4 \mathrm{~d}$ and $\mathrm{e}$ ). Furthermore, electrophoretic mobility shift assays (EMSAs) showed that wogonin suppressed LPS-induced NF- $\kappa$ B DNA-binding activity in a concentration-dependent manner in HCT116 cells (Figure 4f). The results showed that p38 and ERK were activated after LPS administration for 120 and $240 \mathrm{~min}$, and wogonin inhibited the phosphorylation of p38 and ERK (Figure 4g). But JNK and phosphatidylinositol 3-kinase (PI3K)/AKT signaling pathway were only activated at $240 \mathrm{~min}$, but not at $120 \mathrm{~min}$, and wogonin inhibited LPSinduced activation of JNK, AKT and PI3K (Figure 4g). These results indicated that wogonin inhibited the activation of $\mathrm{NF}-\kappa \mathrm{B}$ in LPS-activated HCT116 cells possibly by regulating the MAPK and PI3K/Akt signaling pathways.

Wogonin promotes the activation of Nrf2 pathway in THP-1 cells. As shown in Figures $2 e$ and $f$, wogonin increased the expression of Nrf2 in tumor tissues and surrounding tissues. To further understand the role of Nrf2 signaling on wogonin-induced anti-inflammation in vitro, we next detected the effect of wogonin on the activation of Nrf2 in THP-1 cells. Western blot analysis showed that the Nrf2 nuclear translocation was increased by wogonin (Figures $5 \mathrm{a}$ and b). Immunoprecipitation assay showed that wogonin decreased the Keap1 binding to Nrf2 in THP-1 cells treated with MG132 - a protease inhibitor, and a more extensively ubiquitinated-Keap1 protein was observed in the wogonintreated cells (Figures $5 c$ and d). As MG132 inhibited the degradation of Keap1, the binding of Keap1 and Nrf2 or ubiquitin was observed at the same level of Keap1, excluding other influencing factors. These findings suggested that wogonin might increase Nrf2 protein stability by downregulating Keap1 expression and the interaction between Keap1 and Nrf2.

Furthermore, EMSAs showed that wogonin promoted LPS-stimulated Nrf2 DNA-binding activity in THP-1 cells (Figure 5e). Consistent with these results, the expression of downstream protein $\mathrm{HO}-1$ was significantly increased by administration of wogonin (Figure $5 \mathrm{f}$ ).

Subsequently, Nrf2 siRNA was used to detect whether the anti-inflammatory effect of wogonin was related to Nrf2 signaling pathway in vitro. In addition, Figure $5 \mathrm{~g}$ showed that Nrf2 siRNA pretreatment reversed, at least partially, the inhibitory effect of wogonin on the LPS-induced secretion of IL- 6 and IL- $1 \beta$ in THP1 cells. This suggested that Nrf2 was involved in the wogonininduced inhibition of cytokine secretion.

Wogonin increases the activation of Nrf2 signaling pathway in HCT116 cells. The activation of Nrf2 and consequent upregulation of its target genes not only counteract oxidative and electrophilic assault but also limit the severity of inflammatory tissue damage, which represent a potential mechanism of cancer chemoprevention. ${ }^{27,28}$ For the role of Nrf2 in the prevention of malignant transformation, we next detected the effect of wogonin on the activation of Nrf2 signaling pathway in HCT116 cells. As shown in Figures $6 \mathrm{a}$ and $\mathrm{b}$, LPS-stimulated Nrf2 nuclear translocation was increased by wogonin. The results further confirmed that wogonin promoted the nuclear translocation of Nrf2 as shown by immunofluorescence confocal microscopy (Figure 6c). Immunoprecipitation assay showed that wogonin decreased the Keap1 binding to Nrf2 and ubiquitinated Nrf2 protein in HCT116 cells treated with MG132 (Figures $6 \mathrm{~d}$ and e). Furthermore, EMSAs showed that wogonin promoted the Nrf2 DNA-binding activity in HCT116 cells (Figure 6f). HCT116 cells were co-transfected with GFP and the pARELuc plasmid. LPS treatment resulted in an increase in luciferase activity, and the increase was enhanced by the addition of wogonin (Figure $6 \mathrm{~g}$ ). Then, ChIP assay was carried out to assess whether wogonin impeded binding of Nrf2 to endogenous antioxidant response element. Indeed, the binding activity was significantly increased in HCT116 cells treated with wogonin by detecting mRNA expression of Nrf2 downstream protein $\mathrm{HO}-1$ using $\mathrm{CHIP}$ assay (Figure 6h). Consistent with these results, NQO-1 expression had a significant increase after being treated with wogonin for 1 and $2 \mathrm{~h}$. For the result of HO-1 expression, we considered that the increase was presented at $8 \mathrm{~h}$ (Figures $6 \mathrm{i}$ and $\mathrm{j}$ ).

\section{Discussion}

The six hallmarks of cancer described by Hanahan and Weinberg in 2000 included sustaining proliferative signaling, evading growth suppressors, resisting cell death, enabling replicative immortality, inducing angiogenesis, and activating invasion and metastasis. Increasing evidence suggested that a seventh feature should make this list: inflammation. ${ }^{29}$ The major tumor-promoting mechanism of inflammation is

Figure 3 Effect of wogonin on the growth of HCT116 cells cocultured with LPS-induced THP-1 cells, the expression of inflammatory cytokines and NF- $\kappa$ B in human THP-1 monocytes. (a) MTT assay was performed to detect the anti-proliferation effect of wogonin. HCT-116 cells were seeded at a density of $4 \times 10^{4}$ cells/well and cultured with or without the supernatant of THP-1 cells at ratios of $1: 5,1: 10$ and $1: 20$. LPS $(10 \mu \mathrm{g} / \mathrm{ml})$ and wogonin $(50 \mu \mathrm{M})$ were used in this culture system. ${ }^{\star} P<0.05$, ${ }^{\star \star} P<0.01$ and $n=5$. (b) PCNA expression was analyzed by western blots. (c) Ki67 immunohistochemistry of HCT116 cells in conditional culture system. The production of IL-6 (d) and IL-1 $\beta$ (e) was measured in the culture medium using ELISA kits. (f) The mRNA levels of IL- 6 and IL-1 $\beta$ were measured by real-time RT-PCR. All data are expressed as the mean \pm S.D., ${ }^{\star} P<0.05,{ }^{* \star} P<0.01$ compared with control group; ${ }^{\#} P<0.05$, ${ }^{\# \#} P<0.01$ versus LPS group. After the isolation of nuclear and cytoplasm extracts, NF- $\kappa$ B p65 nuclear expression $(\mathbf{g})$, I $\kappa$ B phosphorylation (h) and IKK phosphorylation (i) were measured by western blotting. (j) The production of IL- 6 and IL-1 $\beta$ in THP-1 cells transfected with NF- $\kappa$ B p65 plasmid was measured in the culture medium using ELISA kits. ${ }^{* *} P<0.01$ compared with LPS alone; ${ }^{\#} P<0.05$, \#\# $P<0.01$ versus LPS + wogonin group 
a

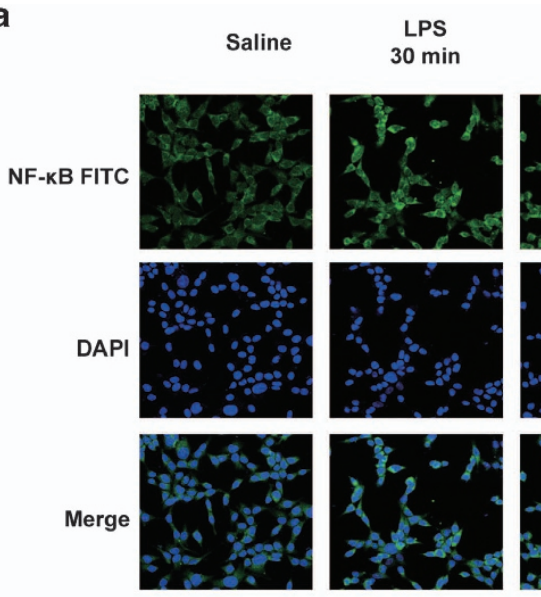

c

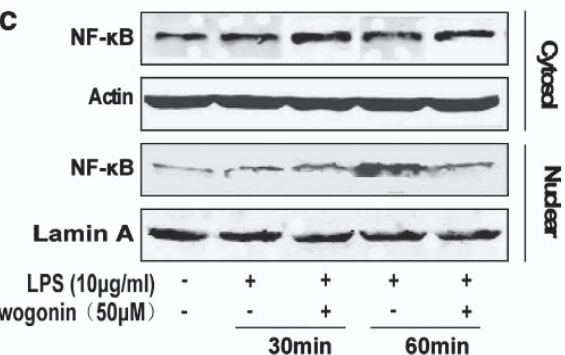

d

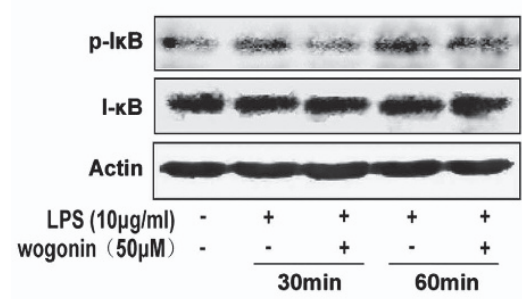

e

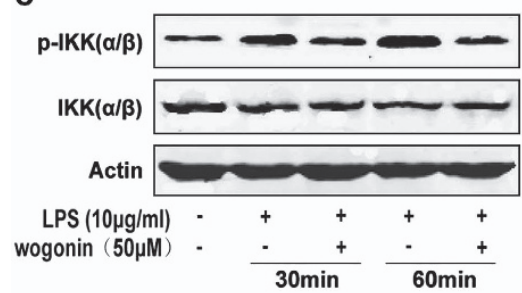

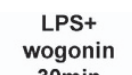

$30 \mathrm{~min}$
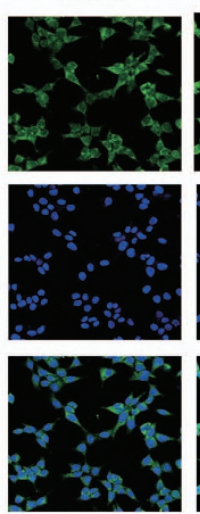
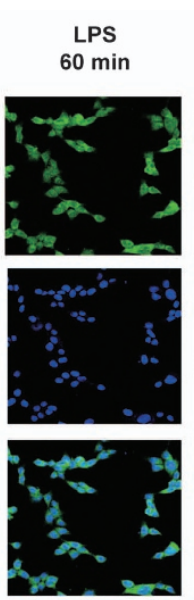

LPS+ wogonin
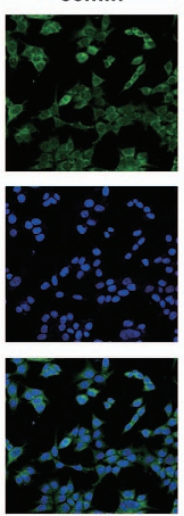

LPS (10 $10 \mathrm{~g} / \mathrm{ml})$ -
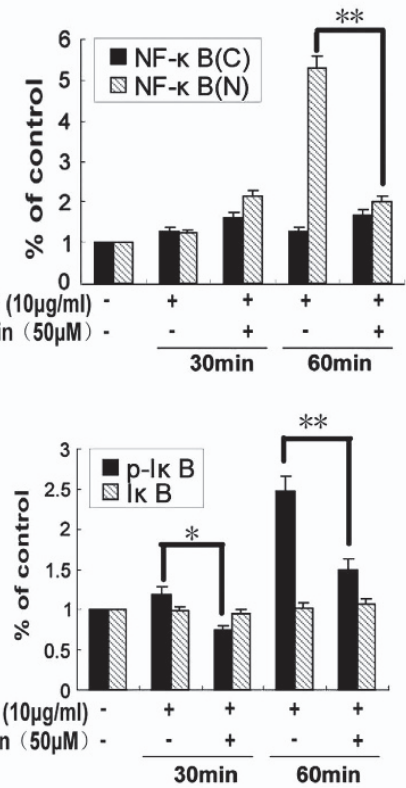

wogonin $(50 \mu \mathrm{M})$.

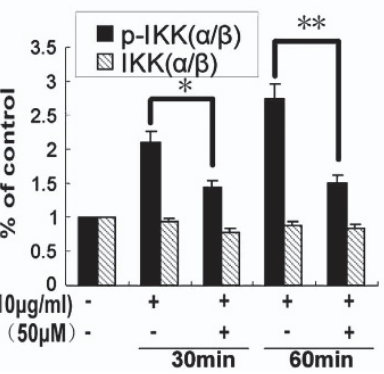

b

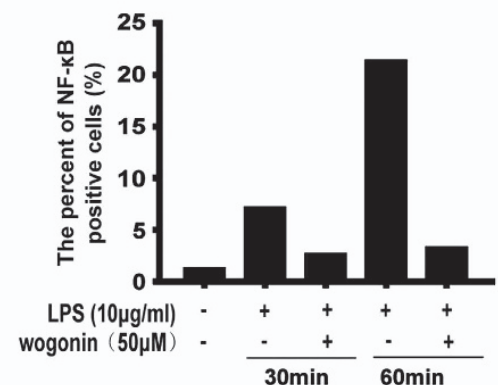

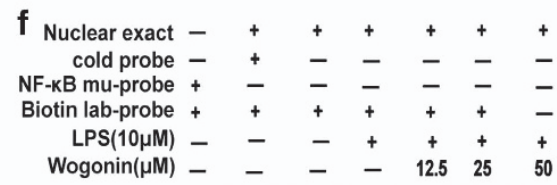

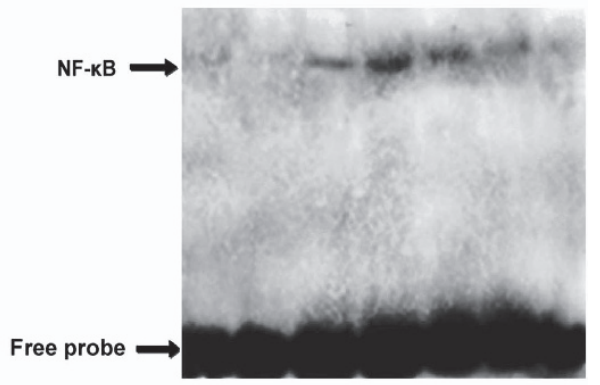

g

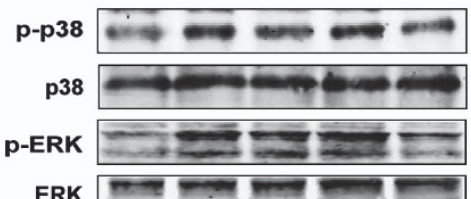

ERK

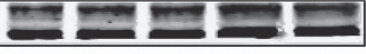

p-JNK

JNK $\doteq$

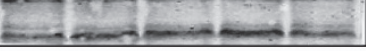

p-Akt

Akt
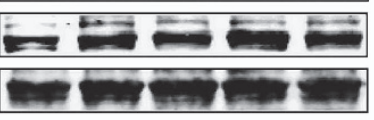

PI3K

Actin

wogonin $(50 \mu \mathrm{M})$

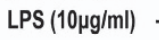

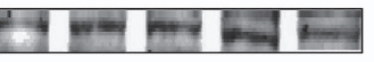

wogonin $(50 \mu \mathrm{M})$

Figure 4 Effect of wogonin on LPS-induced activation of NF- $\kappa$ B signaling pathway in HCT116 cells. (a) Immunofluorescence was performed to analyze NF- $\kappa$ B $p 65$ nuclear translocation. (b) The percentage of cells with NF- $\kappa$ B translocation to the nucleus was shown. (c) Western blotting was performed to analyze NF- $\kappa$ B p65 nuclear translocation. Lamin $\mathrm{A}$ and $\beta$-actin were used as nuclear and cytoplasmic markers, respectively. Whole-cell lysates were analyzed by western blotting using various antibodies against $\mathrm{p}-\mathrm{I}_{\kappa} \mathrm{B} \alpha(\mathrm{d})$ and $\mathrm{p}-\mathrm{IKK}(\mathrm{e})$. Experiments were repeated three times with similar observations in each experiment. Densitometric analysis was performed to determine the relative ratios of each protein. All data are expressed as the mean \pm S.D., ${ }^{*} P<0.05,{ }^{* *} P<0.01$ versus LPS group. (f) Nuclear extracts were prepared and subjected to EMSA to detect NF- $\kappa$ B activation. Arrowhead indicates the DNA-binding activity of NF- $\kappa$ B. Binding is competed by unlabeled NF- $\kappa$ B oligonucleotides (cold) and shifted by the addition of a p65 antibody. (g) Effects of wogonin on the LPS-induced PI3K and MAPK signaling pathway components. HCT116 cells were treated with $50 \mu \mathrm{M}$ wogonin for 120 and $240 \mathrm{~min}$ before the addition of $10 \mu \mathrm{g} / \mathrm{ml}$ LPS

that cytokines produced by immune/inflammatory cells result in the activation of transcription factors, such as NF- $\kappa$ B, STAT3 and AP-1 in premalignant cells, which induce genes expression that stimulates cell proliferation and survival. In other words, the inflammatory microenvironment becomes an integral and essential part of the cancer, and it is considered as a target for cancer therapy. ${ }^{30}$ In our study, AOM-DSS treatment caused extensive high-grade dysplasia and formed 

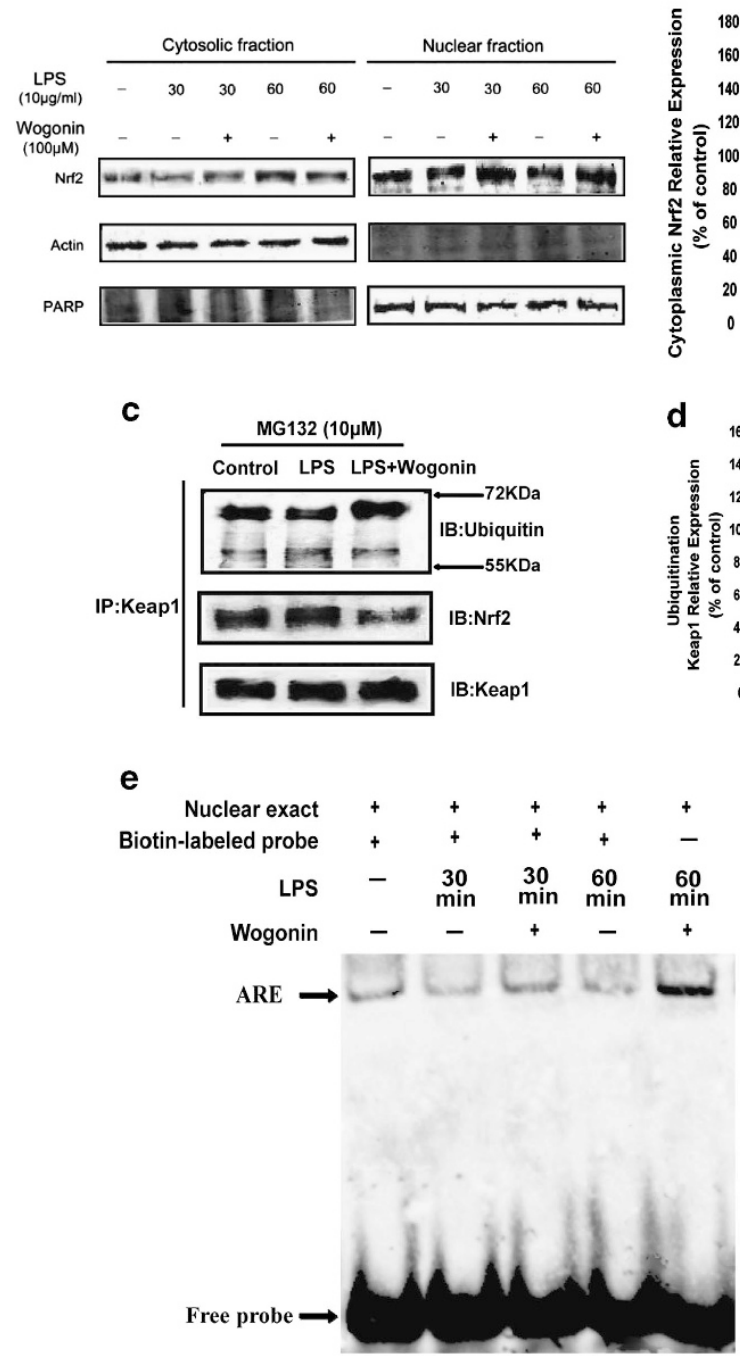

b
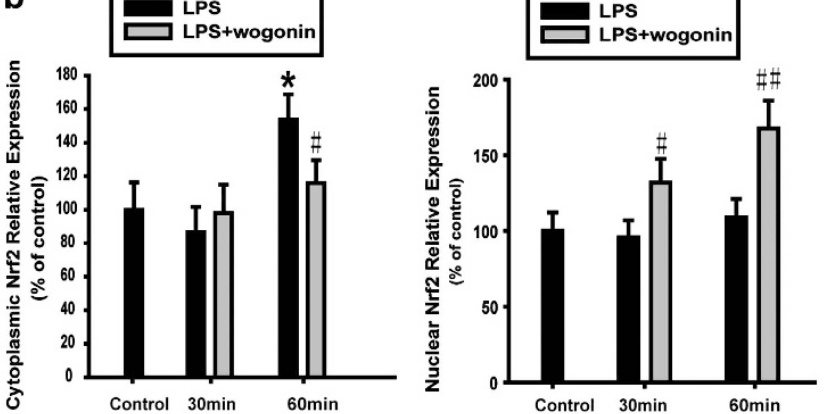

d
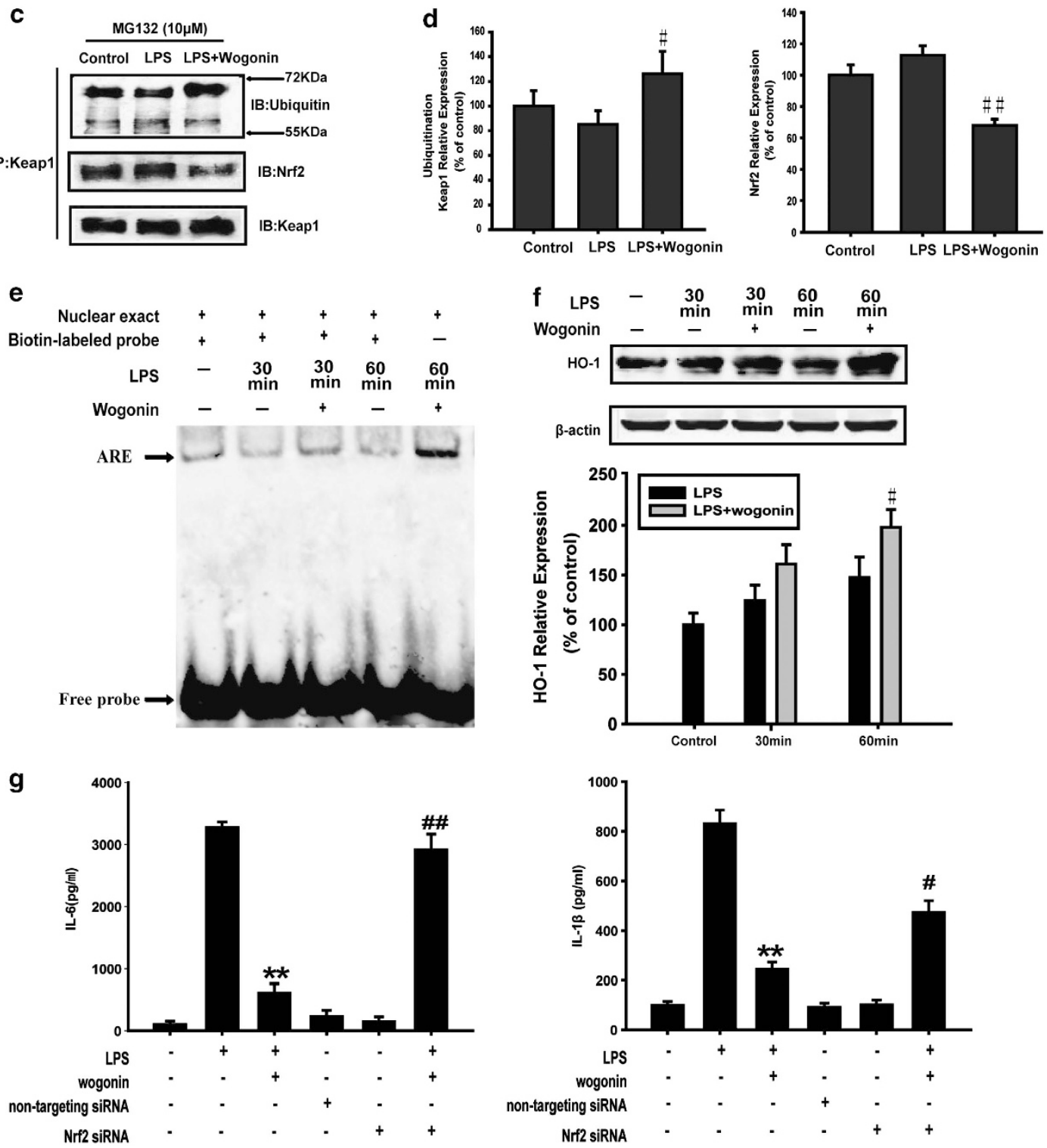

Figure 5 Effect of wogonin on the expression and activation of Nrf2 in LPS-treated THP-1 cells. THP-1 cells were treated with wogonin in the presence of LPS for 30 and $60 \mathrm{~min}$. (a) Nrf2 nuclear translocation was measured by western blotting. (b) Densitometric analysis was performed to determine the relative ratios of each protein. All data are expressed as the mean \pm S.D., ${ }^{*} P<0.05,{ }^{* *} P<0.01$ compared with control group; ${ }^{\#} P<0.05,{ }^{\# \#} P<0.01$ versus LPS alone. (c) Immunoprecipitation assay was used to detect the ubiquitination of Keap1 and the binding of Keap1 and Nrf2. (d) Densitometric analysis was performed to determine the relative ratios of each protein. All data are expressed as the mean \pm S.D., ${ }^{\#} P<0.05,{ }^{\#} P<0.01$ versus LPS alone. (e) Nuclear extracts were prepared and subjected to EMSA to examine Nrf2 activation. Arrowhead indicates the DNA-binding activity of Nrf2. (f) HO-1 expression in whole-cell lysate was measured by western blotting. Densitometric analysis was performed to determine the relative ratios of HO-1 protein. All data are expressed as the mean \pm S.D., ${ }^{\#} P<0.05$, ${ }^{\# \#} P<0.01$ versus LPS group. (g) The production of IL- 6 and IL- $1 \beta$ in the culture medium of THP-1 cells transfected with Nrf2 siRNA was measured using ELISA kits. ${ }^{* *} P<0.01$ compared with LPS alone; ${ }^{\#} P<0.05,{ }^{\# \#} P<0.01$ versus LPS + wogonin group 

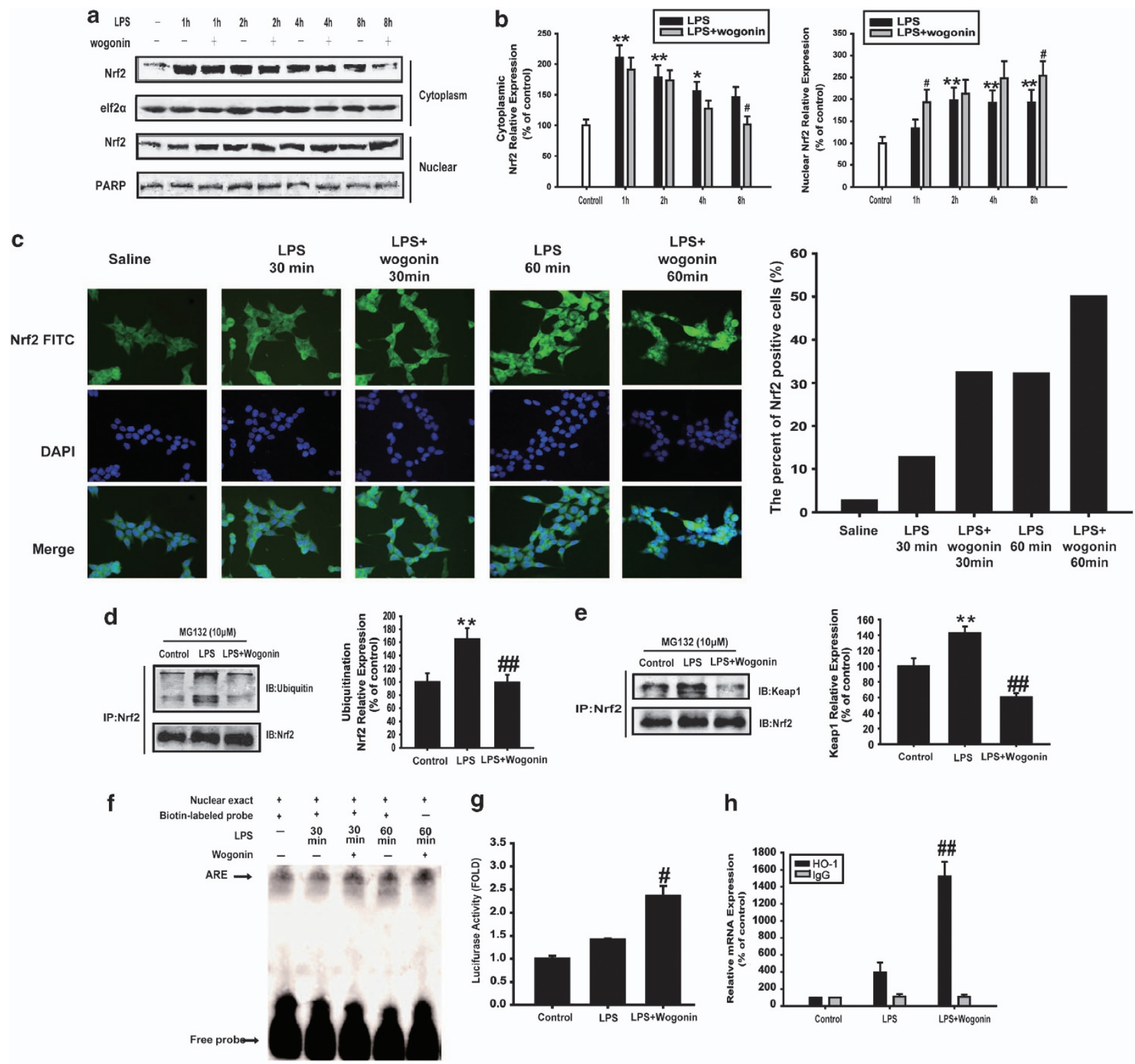

g

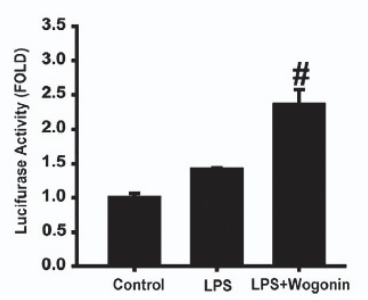

h

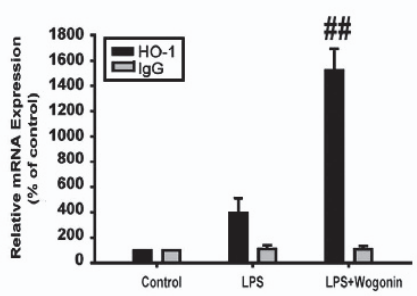

i

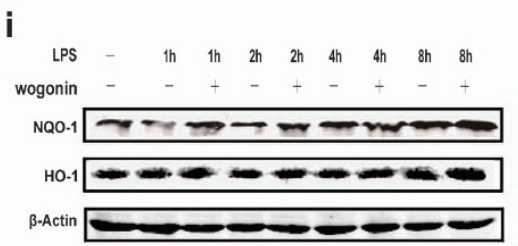

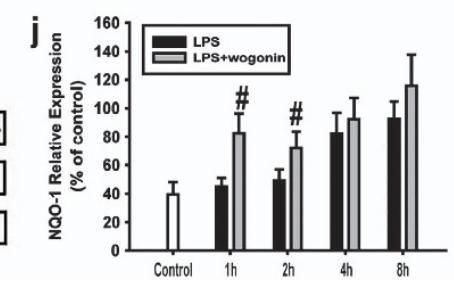

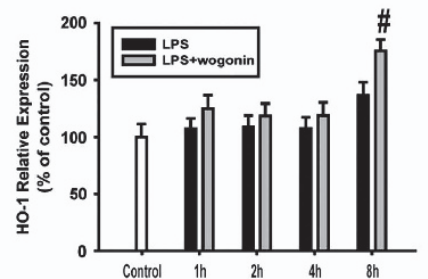

Figure 6 Effect of wogonin on the expression and activation of Nrf2 in LPS-treated HCT116 cells. (a) Nrf2 nuclear translocation was detected by western blotting. PARP and elf2 $\alpha$ were used as nuclear and cytoplasmic markers, respectively. (b) Densitometric analysis was performed to determine the relative ratio of each protein. All data are expressed as the mean \pm S.D., ${ }^{*} P<0.05$, ${ }^{* \star} P<0.01$ compared with control; ${ }^{\#} P<0.05$, ${ }^{\# \#} P<0.01$ versus LPS alone. (c) Nrf2 nuclear translocation was detected by immunofluorescence, and the counting of the percentage of the NF- $\kappa$ B or Nrf2 translocation to the nucleus was shown. (d) Immunoprecipitation assay was used to examine the ubiquitination of Nrf2. Densitometric analysis was performed to determine the relative ratio of each protein. All data are expressed as the mean $\pm S$.D., ${ }^{*} P<0.05,{ }^{* *} P<0.01$ compared with control group; ${ }^{\#} P<0.05,{ }^{\# \#} P<0.01$ versus LPS alone. (e) Effect of wogonin on the binding of Keap1 and Nrf2. Densitometric analysis was performed to determine the relative ratios of each protein. All data are expressed as the mean \pm S.D., ${ }^{*} P<0.05,{ }^{* \star} P<0.01$ compared with control group; ${ }^{\#} P<0.05$, ${ }^{\# \#} P<0.01$ versus LPS alone. (f) EMSA to detect the Nrf2 DNA-binding activity. Arrowhead indicates the DNA-binding activity of Nrf2. (g) HCT116 cells were transiently transfected with an Nrf2 reporter gene plasmid for $4 \mathrm{~h}$. The luciferase activities were detected. All data are expressed as the mean \pm S.D., ${ }^{\#} P<0.05,{ }^{\# \#} P<0.01$ versus LPS alone. (h) ChIP assay indicated that the binding of Nrf2 and ARE by detect HO-1 mRNA expression using real-time PCR. All data are expressed as the mean \pm S.D., ${ }^{\#} P<0.05$, ${ }^{\#} P<0.01$ versus LPS alone. (i) NQO-1 and HO-1 expressions in whole-cell lysate were measured by western blotting. (j) Densitometric analysis was performed to determine the relative ratios of each protein. All data are expressed as the mean \pm S.D., ${ }^{\star} P<0.05$, ${ }^{\star *} P<0.01$ compared with control; ${ }^{\#} P<0.05$, ${ }^{\# \#} P<0.01$ versus LPS alone 
adenomas in colorectal tissue, and wogonin exhibited a remarkable ability to reduce intestinal inflammation and prevent carcinogenesis induced by AOM/DSS with no side effect for long-term administration (Figures 1 and 2; Tables 1 and 2). It is extremely important for cancer prevention because it needs long-term administration. However, the target for wogonin remains to be further investigated. In this study, we demonstrated the effect of wogonin on NF- $\kappa \mathrm{B}$ and Nrf2 signaling pathways at different stages of inflammation induced by AOM/DSS in vivo and the effect on the expression and nuclear localization of $\mathrm{NF}-\kappa \mathrm{B}$ and $\mathrm{Nrf2}$ in vitro. The in vivo and in vitro studies were used as the previous study. ${ }^{21,31-33}$ Our results indicated that downregulated NF- $\kappa \mathrm{B}$ and upregulated Nrf2 may provide mechanistic links between inflammation and cancer.

Nrf2 induces the gene expression of antioxidant and detoxification enzymes and has been reported to exert antiinflammatory effect by regulating several pro-inflammatory genes, including TNF- $\alpha, \mathrm{IL}-1 \beta$ and IL- 6 in inflammatory cells. $^{34-36}$ Therefore, we could believe that boosting the Nrf2-dependent response to counteract environmental stress is a promising strategy for inflammation-related cancer prevention. In our study, we found that wogonin increased the expression of Nrf2 in surrounding tissues of AOM/DSStreated mice. In in vitro study, wogonin promoted the nuclear expression of Nrf2 in THP-1 cells and HCT116 cells (Figures 5 and 6). We can conclude that Nrf2 might inhibit the production of cytokines in THP-1 cells, and exert the effect of chemoprevention in HCT116 cells. However, we found that high expression of Nrf2 is detected in tumor tissues, and wogonin did not induce more Nrf2 expression (Figures $2 \mathrm{f}-\mathrm{i}$ ). This finding could be attributed to the 'dark side' of Nrf2. As we know, Nrf2 has also been demonstrated to be beneficial for tumor survival, which could decrease the accumulation of ROS, maintain a favorable redox balance and upregulate ARE-dependent genes to generate antioxidants in cancer cells to promote their survival and development. ${ }^{37-41}$ Moreover, several oncogenes, such as K-Ras, B-Raf and Myc, have been shown to actively induce transcription of Nrf2, promoting a ROS detoxification program that creates a permissive environment for tumor formation. ${ }^{10}$ It seems that Nrf2 is an advantage for cancer development and should be inhibited rather than induction during cancer therapy. However, it is believed that compounds able to induce Nrf2-dependent response to counteract environmental stress is a promising strategy in a number of diseases, ${ }^{42,43}$ and it is optimistic to discover new Nrf2 activators for chemoprevention.

The coordinated regulation of Nrf2 and NF- $\kappa \mathrm{B}$ has been shown to have a crucial role in translating cellular stress signal into an anti-inflammatory response. Multiple lines of evidence suggest that genetic disruption or pharmacologic inhibition of Nrf2 signaling augments the expression and/or activity of proinflammatory mediators and sustains inflammation. ${ }^{28}$ As NF$\kappa \mathrm{B}$ has been recognized as an important molecular link between inflammation and cancer, it is possible that the antiinflammatory and chemopreventive effects of Nrf2 inducers or Nrf2-regulated gene products may be mediated through downregulation of NF- $\kappa \mathrm{B}$. It is reported that levels of $\mathrm{NF}-\kappa \mathrm{B}$ and cytokines in Nrf2-null mice were significantly higher than those in Nrf2 wild-type mice. ${ }^{44,45}$ Many chemopreventive phytochemicals exhibited simultaneous induction of Nrf2regulated cytoprotective protein expression and inhibition of NF- $\kappa$ B-regulated pro-inflammatory signaling. ${ }^{27}$ Our study also demonstrated that wogonin inhibited the activation of $\mathrm{NF}-\kappa \mathrm{B}$ signaling pathway and induced Nrf2 signaling pathway in vivo and in vitro. However, direct evidence linking Nrf2 activation to $\mathrm{NF}-\kappa \mathrm{B}$ downregulation is yet to be established. We intend to explore the molecular link between the two pathways using Nrf2-knockout mice in the future study.

IL-6 and IL-1 $\beta$ contribute to cellular transformation and growth in a paracrine or autocrine manner. ${ }^{46}$ We observed that wogonin suppressed the transcription of IL-6 and IL- $1 \beta$ in surrounding tissues of AOM/DSS-treated mice (Figures 2c and d). In addition, our results showed that wogonin treatment significantly suppressed the secretion of IL- 6 and IL-1 $\beta$ and downregulated the mRNA levels of IL- 6 and IL- $1 \beta$ in THP-1 cells (Figures $3 d-f$ ). All above results indicated that wogonin suppressed the production of IL- 6 and IL- $1 \beta$ by modulating $\mathrm{NF}-\kappa \mathrm{B}$ and Nrf2 signaling pathways.

Taken together, our results showed that wogonin prevented the initiation and development of $\mathrm{CAC}$ and regulated $\mathrm{NF}-\kappa \mathrm{B}$ and Nrf2 signaling pathways in vivo and in vitro. NF- $\kappa \mathrm{B}$ and Nrf2 signaling pathways could be critical for wogonin's prevention of CAC. Therefore, wogonin might be a new and attractive chemoprevention agent for inflammation-related cancer.

\section{Materials and Methods}

Reagents and cell culture. Wogonin (purity $>99 \%$ ) was provided by Dr. Zhiyu Li from the College of Pharmacy, China Pharmaceutical University. In in vitro study, wogonin was dissolved in dimethyl sulfoxide (DMSO) as a stock solution $(100 \mathrm{mM})$, and stored at $-20^{\circ} \mathrm{C}$, freshly diluted with Dulbecco's Modified Eagle Medium (Gibco, Invitrogen, Carlsbad, CA, USA) to the final concentration $(50 \mu \mathrm{M})$. In in vivo study, wogonin $(25 \mathrm{mg} / \mathrm{bottle})$ was made into freeze-dried powder formulation by $\mathrm{Dr}$. Xue Ke from college of pharmacy, China pharmaceutical university, and we administrated wogonin $(60 \mathrm{mg} / \mathrm{kg}$, i.g.) in mice.

LPS was purchased from Sigma (St. Louis, MN, USA). Primary antibodies against p38, p-p38, ERK, p-ERK, JNK, p-JNK, PI3K, Akt, p-Akt (Ser 473), Lamin A, IL-1 $\beta, \mathrm{IL}-6, \mathrm{I} \kappa \mathrm{B}, \mathrm{NF}-\kappa \mathrm{B}$, Keap1, HO-1, NQO-1 and Nrf2 were obtained from Santa Cruz Biotechnology (Santa Cruz, CA, USA); antibodies against bcl-2, PARP, $p-I_{\kappa} B$, IKK, $p-\mid K K \alpha / \beta$ and PCNA were from Cell Signaling Technology (Danvers, MA, USA); and antibodies against $\beta$-actin were from Boster (Wuhan, China). IRDyeTM800 conjugated secondary antibodies were obtained from Rockland Inc. (Philadelphia, PA, USA). Human colon carcinoma HCT116 cells and human acute monocytic leukemia THP-1 cells were obtained from CBCAS (Cell Bank of the Chinese Academic of Sciences, Shanghai, China). HCT116 cells and THP-1 cells were cultured in McCoy's 5A medium (Sigma) and RPMI-1640 medium (Gibco, Carlsbad, CA, USA), supplemented with $10 \%$ fetal bovine serum (Sijiqing, Hangzhou, China), $100 \mathrm{U} / \mathrm{ml}$ benzyl penicillin and $100 \mu \mathrm{g} / \mathrm{ml}$ streptomycin. Cells were cultured in a humidified environment with $5 \% \mathrm{CO}_{2}$ at $37^{\circ} \mathrm{C}$.

Animal models. C57BL/6 mice, $6-8$ weeks old, weighing $18-22 \mathrm{~g}$, were supplied by Shanghai Laboratory Animal Center, China Academy of Sciences (Certificate No. 122). The mice were raised in air-conditioned rooms under controlled lighting (12 h light/day) and provided with food and water at discretion. Animal care and surgery protocols were approved by the Animal Care Committee of China Pharmaceutical University. All animals were treated and used in a scientifically valid and ethical manner. A total of 84 mice were randomly divided into the following 12 groups: saline 29 days' group (negative control group), $n=6$; AOM/DSS 29 days' group, $n=6$; AOM/DSS + wogonin 29 days' group, $n=6$; saline 48 days' group (negative control group), $n=6$; AOM/DSS 48 days' group, $n=6 ; A O M / D S S$ + wogonin 48 days' group, $n=6$; saline 68 days' group (negative control group), $n=6$; AOM/DSS 68 days' group, AOM/DSS + wogonin 68 days' group, $n=6$; saline 105 days' group (negative control group), $n=10$; AOM/DSS 105 days' group, $n=10$; and AOM/DSS + wogonin 105 days' group, $n=10$. 
CAC was induced as described previously. ${ }^{2}$ Briefly, on day 1 , mice were injected intraperitoneally (i.p.) with $12.5 \mathrm{mg} / \mathrm{kg} \mathrm{AOM} \mathrm{(Sigma)} \mathrm{and} \mathrm{maintained} \mathrm{on} \mathrm{a} \mathrm{regular}$ diet and water for 5 days. After 5 days, mice received 2.5\% DSS (molecular weight $35000-50000 \mathrm{kDa}$, MP Biomedicals Inc., Irvine, CA, USA) in drinking water for 5 days. After this, mice were maintained on regular water for 14 days and subjected to two more DSS treatment cycles. The mice were given wogonin $60 \mathrm{mg} / \mathrm{kg}$ every day via gastric intubation starting 5 days before the $\mathrm{AOM}$ injection, until the termination of the experiment. Body weight was measured every week. On day 106, mice were killed. Macroscopic tumors were counted and measured with a caliper. The clinical course of the disease was followed daily by measuring body weight and monitoring for signs of rectal bleeding or diarrhea.

Histological analysis and immunohistochemistry. Four-micronthick sections were prepared from formalin-fixed, paraffin-embedded colon tissue from AOM/DSS-treated mice and stained with $\mathrm{H} \& \mathrm{E}$. Immunohistochemical staining against BrdU, PCNA, IL-1 $\beta$, IL-6, NF- $\kappa$ B and Nrf2 was performed with standard techniques. Image pro plus software was used to analyze the number of positive cells by detecting IOD.

Immunofluorescence confocal microscopy. HCT116 cells were seeded onto glass coverslips in six-well plates, and after $24 \mathrm{~h}$, treated with wogonin as indicated, and subjected to immunofluorescence staining as described in previous study. ${ }^{47}$

Preparation of cytosolic and nuclear extracts and whole-cell lysates. Nuclear and cytosolic protein extracts were prepared according to the modified method as described. ${ }^{48}$ One part of the cytosolic and nuclear fractions was subjected to immunoblot analysis. The rest of the nuclear extract was used for EMSA. The whole-cell lysates were prepared as mentioned. ${ }^{48}$

Electrophoretic mobility shift assay. Nuclear extracts $(8 \mu \mathrm{g} / \mathrm{sample})$ were prepared as previously described and incubated with biotin-labeled NF- $\kappa \mathrm{B}$ and ARE consensus oligonucleotides in reaction buffer for $20 \mathrm{~min}$ at room temperature. A double-stranded mutated oligonucleotide was used to evaluate the specificity of NF- $\kappa$ B and Nrf2 binding to DNA. The specificity was also determined through competition with the unlabeled oligonucleotide. This assay was carried out as previously described.

Western blotting analysis. HCT116 and THP-1 cells were treated with various concentrations of wogonin for the indicated times with or without LPS $(10 \mu \mathrm{g} / \mathrm{ml})$. Cell and tissue lysates were analyzed by western blotting as described previously. ${ }^{49}$

Culture of HCT116 cells with conditioned media from LPSinduced THP-1. THP-1 cells were cultured in 24-well tissue culture plates at THP-1: HCT116 ratios of $20: 1,10: 1$ and $5: 1$. THP-1 cells were left untreated or activated with LPS. HCT116 cells were seeded in another 24-well tissue culture plate (Costar, Cambridge, MA, USA) at $1.6 \times 10^{4}$ cells per well, grown to $80 \%$ confluence one day before treatment. Cells were (1) left untreated or treated with (2) $10 \mu \mathrm{g} / \mathrm{ml}$ LPS, (3) $10 \mu \mathrm{g} / \mathrm{ml}$ LPS $+50 \mu \mathrm{M}$ wogonin, (4) conditioned media from LPS-activated THP-1 cells or (5) conditioned media from LPS-activated THP-1 cells and wogonin together. Then, we used 3-(4,5-dimethylthiazol-2-yl)-2,5-diphenyltetrazolium bromide (MTT) assay to detect the anti-proliferation effect of wogonin. HCT116 cells were left to adhere overnight, then exposed to five groups of medium for $24 \mathrm{~h}$. Subsequently, $20 \mu \mathrm{l}$ of MTT solution $(5 \mathrm{mg} / \mathrm{ml})$ was transferred to each well. Plates were incubated for $4 \mathrm{~h}$ at $37^{\circ} \mathrm{C}$ and $5 \% \mathrm{CO}_{2}$. After Incubation, supernatants were removed, and $100 \mu \mathrm{l}$ DMSO was added to ensure total solubility of formazan crystals. Plates were placed on an orbital shaker for $2 \mathrm{~min}$, and the absorbance was recorded at $570 \mathrm{~nm}$ using a Universal Microplate Reader (EL800, BIO-TEK Instruments Inc., Winooski, VT, USA).

Ki67 proliferation assay. THP-1 cells were cultured in six-well tissue culture plates at THP-1: HCT116 ratio of 10:1. THP-1 cells were left untreated or activated with LPS. HCT116 cells were seeded in another six-well tissue culture plate (Costar) at $1.6 \times 10^{4}$ cells per well, grown to $80 \%$ confluence one day before treatment. Cells were (1) left untreated or treated with (2) $10 \mu \mathrm{g} / \mathrm{ml} \mathrm{LPS,} \mathrm{(3)} 10 \mu \mathrm{g} / \mathrm{ml}$ LPS $+50 \mu \mathrm{M}$ wogonin, (4) conditioned media from LPS-activated THP-1 cells or (5) conditioned media from LPS-activated THP-1 cells and wogonin together. Then, immunohistochemical staining against Ki67 was performed with standard techniques.
Cytokine quantification by enzyme-linked immunosorbent assay. IL- 6 and IL- $1 \beta$ secretions in cell supernatants were collected at various time points after LPS induction and in the homogenate of surrounding tissues were measured by the Mouse and Human IL- 6 and IL-1 $\beta$ ELISA kits (KeyGEN, Nanjing, China) according to the manufacturer's instructions. The experiments were repeated three times. Levels of cytokines were expressed in $\mathrm{pg} / \mathrm{ml}$.

Quantitative real-time PCR. The RNA extracts of cells and tissues were prepared according to the modified method as described. ${ }^{48}$ The relative amount of target mRNA was determined using the comparative threshold $\left(C_{t}\right)$ method by normalizing target mRNA $C_{\mathrm{t}}$ values to those for $\beta$-Actin $\left(\Delta C_{\mathrm{t}}\right)$. The sample of surrounding tissues was also operated as described. The primer sequences were as follows:

- Human IL-6-sense (5'-TGTAGTGAGGAACAAGCCAGAG-3');

- Human IL-6-antisense (5'-TACATTTGCCGAAGAGCC-3');

- Human IL-1 $\beta$-sense ( $5^{\prime}$-AGGCTGCTCTGGGATTC-3');

- Human IL-1 $\beta$-antisense (5'-GCCACAACAACTGACGC-3');

- Human $\beta$-Actin-sense (5'-CTGTCCCTGTATGCCTCT-3');

- Human $\beta$-Actin-antisense (5'-ATGTCACGCACGATTTCC-3')

- Mouse IL-6-sense (5'-ACAACCACGGCCTTCCCTAC-3');

- Mouse IL-6-antisense (5'-TCTCATTTCCACGATTTCCCAG-3');

- Mouse IL-1 $\beta$-sense (5'-CCAAGCTTCCTTGTGCAAGTA-3');

- Mouse IL-1 $\beta$-antisense (5'-AAGCCCAAAGTCCATCAGTGG-3');

- Mouse $\beta$-actin-sense (5'-TGCTGTCCCTGTATGCCTCT-3');

- Mouse $\beta$-actin-antisense (5'-TTTGATGTCACGCACGCACGATTT-3').

Transfection of NF- $\kappa$ B plasmid and Nrf2 siRNA. THP-1 cells were plated in six-well plates with fresh medium. NF- $\kappa$ B plasmid and Nrf2 siRNA transfections were performed according to the manufacturer's instructions of Lipofectamine 2000 reagent (Invitrogen, Carlsbad, CA, USA). After that, THP-1 cells were incubated with $10 \mu \mathrm{g} / \mathrm{ml} \mathrm{LPS} \mathrm{combined} \mathrm{with} 50 \mu \mathrm{M}$ wogonin for $12 \mathrm{~h}$ at $37^{\circ} \mathrm{C}$, and the concentration of cytokines in the supernatant of THP-1 cells were detected.

Statistical analysis. All results in the text are expressed as means \pm S.D. from triplicate experiments performed in a parallel manner unless otherwise indicated. Statistically significant differences (analysis of variance and post hoc tests) were analyzed using the GraphPad Prism software (GraphPad Software Inc., Avenida, CA, USA). Details of each statistical analysis used are provided in the figure legends.

\section{Conflict of Interest}

The authors declare no conflict of interest.

Acknowledgements. This work was supported by the Project Program of State Key Laboratory of Natural Medicines, China Pharmaceutical University (Nos: JKGZ201101, SKLNMZZ201210, SKLNMZZCX201303 and SKLNMZZJQ201302), the Natural Science Foundation of China (No. 91029744, No. 81372268 and No. 81173087), the National Science \& Technology Major Project (No.2012ZX09304-001), the Natural Science Foundation for Distinguished Young Scholars of Jiangsu Province (No. BK20130026) and Program for Changjiang Scholars and Innovative Research Team in University (PCSIRT-IRT1193).

1. Jemal A, Siegel R, Ward E, Hao Y, Xu J, Murray T et al. Cancer statistics, 2008. CA Cancer J Clin 2008; 58: 71-96.

2. Neufert C, Becker C, Neurath MF. An inducible mouse model of colon carcinogenesis for the analysis of sporadic and inflammation-driven tumor progression. Nat Protoc 2007; 2: 1998-2004.

3. Suzuki R, Kohno H, Sugie S, Nakagama H, Tanaka T. Strain differences in the susceptibility to azoxymethane and dextran sodium sulfate-induced colon carcinogenesis in mice. Carcinogenesis 2006; 27: 162-169.

4. Yen D, Cheung J, Scheerens H, Poulet F, McClanahan T, McKenzie B et al. IL-23 is essential for T cell-mediated colitis and promotes inflammation via IL-17 and IL-6. J Clin Invest 2006; 116: 1310-1316. 
5. Yadav A, Kumar B, Datta J, Teknos TN, Kumar P. IL-6 promotes head and neck tumo metastasis by inducing epithelial-mesenchymal transition via the JAK-STAT3-SNAIL signaling pathway. Mol Cancer Res 2011; 9: 1658-1667.

6. Tu S, Bhagat G, Cui G, Takaishi S, Kurt-Jones EA, Rickman B et al. Overexpression of interleukin-1beta induces gastric inflammation and cancer and mobilizes myeloid-derived suppressor cells in mice. Cancer Cell 2008; 14: 408-419.

7. Karin M, Greten FR. NF-kappaB: linking inflammation and immunity to cancer development and progression. Nat Rev Immunol 2005; 5: 749-759.

8. Karin M, Cao Y, Greten FR, Li ZW. NF-kappaB in cancer: from innocent bystander to major culprit. Nat Rev Cancer 2002; 2: 301-310.

9. Motohashi H, Yamamoto M. Nrf2-Keap1 defines a physiologically important stress response mechanism. Trends Mol Med 2004; 10: 549-557.

10. DeNicola GM, Karreth FA, Humpton TJ, Gopinathan A, Wei C, Frese K et al. Oncogeneinduced Nrf2 transcription promotes ROS detoxification and tumorigenesis. Nature 2011; 475: 106-109.

11. Cullinan SB, Gordan JD, Jin J, Harper JW, Diehl JA. The Keap1-BTB protein is an adapto that bridges Nrf2 to a Cul3-based E3 ligase: oxidative stress sensing by a Cul3-Keap1 ligase. Mol Cell Biol 2004; 24: 8477-8486.

12. Zhang DD, Lo SC, Sun Z, Habib GM, Lieberman MW, Hannink M. Ubiquitination of Keap1, a BTB-Kelch substrate adaptor protein for Cul3, targets Keap1 for degradation by a proteasome-independent pathway. J Biol Chem 2005; 280: 30091-30099.

13. Boutten A, Goven D, Artaud-Macari E, Boczkowski J, Bonay M. NRF2 targeting: promising therapeutic strategy in chronic obstructive pulmonary disease. Trends Mol Med 2011; 17: 363-371.

14. Malhotra D, Thimmulappa R, Vij N, Navas-Acien A, Sussan T, Merali S et al. Heightened endoplasmic reticulum stress in the lungs of patients with chronic obstructive pulmonary disease: the role of Nrf2-regulated proteasomal activity. Am J Respir Crit Care Med 2009, 180: 1196-1207.

15. Chi YS, Lim H, Park H, Kim HP. Effects of wogonin, a plant flavone from Scutellaria radix, on skin inflammation: in vivo regulation of inflammation-associated gene expression. Biochem Pharmacol 2003; 66: 1271-1278.

16. Shen SC, Lee WR, Lin HY, Huang HC, Ko CH, Yang LL et al. In vitro and in vivo inhibitory activities of rutin, wogonin, and quercetin on lipopolysaccharide-induced nitric oxide and prostaglandin E(2) production. Eur J Pharmacol 2002; 446: 187-194.

17. Tang NY, Yang JS, Chang YH, Lu HF, Hsia TC, Lin WC et al. Effects of wogonin on the levels of cytokines and functions of leukocytes associated with NF-kappa B expression in Sprague-Dawley rats. In Vivo 2006; 20: 527-532.

18. Zhang YC, Gan FF, Shelar SB, Ng KY, Chew EH. Antioxidant and Nrf2 inducing activities of luteolin, a flavonoid constituent in Ixeris sonchifolia Hance, provide neuroprotective effects against ischemia-induced cellular injury. Food Chem Toxicol 2013; 59: 272-280.

19. Ehren JL, Maher P. Concurrent regulation of the transcription factors Nrf2 and ATF4 mediates the enhancement of glutathione levels by the flavonoid fisetin. Biochem Pharmacol 2013; 85: 1816-1826.

20. Zhai X, Lin M, Zhang F, Hu Y, Xu X, Li Y et al. Dietary flavonoid genistein induces Nrf2 and phase II detoxification gene expression via ERKs and PKC pathways and protects against oxidative stress in Caco-2 cells. Mol Nutr Food Res 2013; 57: 249-259.

21. Liu L, Li YH, Niu YB, Sun Y, Guo ZJ, Li Q et al. An apple oligogalactan prevents against inflammation and carcinogenesis by targeting LPS/TLR4/NF-kappaB pathway in a mouse model of colitis-associated colon cancer. Carcinogenesis 2010; 31: 1822-1832.

22. Nishitani Y, Zhang L, Yoshida M, Azuma T, Kanazawa K, Hashimoto T et al. Intestinal antiinflammatory activity of lentinan: influence on IL-8 and TNFR1 expression in intestinal epithelial cells. PLOS One 2013; 8: e62441.

23. Shaker A, Swietlicki EA, Wang L, Jiang S, Onal B, Bala S et al. Epimorphin deletion protects mice from inflammation-induced colon carcinogenesis and alters stem cell niche myofibroblast secretion. J Clin Invest 2010; 120: 2081-2093.

24. Grivennikov S, Karin E, Terzic J, Mucida D, Yu GY, Vallabhapurapu S et al. IL-6 and Stat3 are required for survival of intestinal epithelial cells and development of colitis-associated cancer. Cancer Cell 2009; 15: 103-113.

25. Ahmed S, Pakozdi A, Koch AE. Regulation of interleukin-1beta-induced chemokine production and matrix metalloproteinase 2 activation by epigallocatechin-3-gallate in rheumatoid arthritis synovial fibroblasts. Arthritis Rheum 2006; 54: 2393-2401.

26. Karin M. Nuclear factor-kappaB in cancer development and progression. Nature 2006; 441 431-436.

27. Surh YJ. NF-kappa B and Nrf2 as potential chemopreventive targets of some antiinflammatory and antioxidative phytonutrients with anti-inflammatory and antioxidative activities. Asia Pac J Clin Nutr 2008; 17(Suppl 1): 269-272.

28. Kundu JK, Surh YJ. Nrf2-Keap1 signaling as a potential target for chemoprevention of inflammation-associated carcinogenesis. Pharm Res 2010; 27: 999-1013.

29. Mantovani A. Cancer: inflaming metastasis. Nature 2009; 457: 36-37.

30. Joyce JA. Therapeutic targeting of the tumor microenvironment. Cancer Cell 2005; 7: 513-520.
31. Weisser SB, Brugger HK, Voglmaier NS, McLarren KW, van Rooijen N, Sly LM. SHIP. deficient, alternatively activated macrophages protect mice during DSS-induced colitis. J Leukoc Biol 2011; 90: 483-492.

32. Song YA, Park YL, Kim KY, Chung CY, Lee GH, Cho DH et al. Black tea extract prevents lipopolysaccharide-induced NF-kappaB signaling and attenuates dextran sulfate sodiuminduced experimental colitis. BMC Complement Altern Med 2011; 11: 91

33. Liu YW, Su YW, Ong WK, Cheng TH, Tsai YC. Oral administration of Lactobacillus plantarum K68 ameliorates DSS-induced ulcerative colitis in BALB/c mice via the anti-inflammatory and immunomodulatory activities. Int Immunopharmacol 2011; 11: 2159-2166.

34. Cai C, Teng L, Vu D, He JQ, Guo Y, Li Q et al. The heme oxygenase 1 inducer (CoPP) protects human cardiac stem cells against apoptosis through activation of the extracellular signal-regulated kinase (ERK)/NRF2 signaling pathway and cytokine release. J Biol Chem 2012; 287: 33720-33732.

35. Wang $\mathrm{H}$, Khor TO, Saw $\mathrm{CL}$, Lin W, Wu T, Huang $\mathrm{Y}$ et al. Role of Nrf2 in suppressing LPS-induced inflammation in mouse peritoneal macrophages by polyunsaturated fatty acids docosahexaenoic acid and eicosapentaenoic acid. Mol Pharm 2010; 7 : 2185-2193.

36. Reddy NM, Kleeberger SR, Kensler TW, Yamamoto M, Hassoun PM, Reddy SP. Disruption of Nrf2 impairs the resolution of hyperoxia-induced acute lung injury and inflammation in mice. J Immunol 2009; 182: 7264-7271.

37. Shen H, Zhou S, Wang J. The paradoxical role of Nrf2 in tumor biology. Crit Rev Eukaryot Gene Expr 2013; 23: 37-47.

38. Akhdar H, Loyer P, Rauch C, Corlu A, Guillouzo A, Morel F. Involvement of Nrf2 activation in resistance to 5-fluorouracil in human colon cancer HT-29 cells. Eur J Cancer 2009; 45 2219-2227.

39. Lau A, Villeneuve NF, Sun Z, Wong PK, Zhang DD. Dual roles of Nrf2 in cancer. Pharmacol Res 2008; 58: 262-270.

40. Chen N, Yi X, Abushahin N, Pang S, Zhang D, Kong B et al. Nrf2 expression in endometrial serous carcinomas and its precancers. Int J Clin Exp Pathol 2010; 4: 85-96.

41. Stacy DR, Ely K, Massion PP, Yarbrough WG, Hallahan DE, Sekhar KR et al. Increased expression of nuclear factor E2 p45-related factor 2 (NRF2) in head and neck squamous cell carcinomas. Head Neck 2006; 28: 813-818.

42. Cheng JH, Hung CF, Yang SC, Wang JP, Won SJ, Lin CN. Synthesis and cytotoxic, antiinflammatory, and anti-oxidant activities of 2',5'-dialkoxylchalcones as cancer chemopreventive agents. Bioorg Med Chem 2008; 16: 7270-7276.

43. Wu TY, Khor TO, Saw CL, Loh SC, Chen Al, Lim SS et al. Anti-inflammatory/Anti-oxidative stress activities and differential regulation of Nrf2-mediated genes by non-polar fractions of tea Chrysanthemum zawadskii and licorice Glycyrrhiza uralensis. AAPS J 2011; 13: $1-13$

44. Jin W, Zhu L, Guan Q, Chen G, Wang QF, Yin HX et al. Influence of Nrf2 genotype on pulmonary NF-kappaB activity and inflammatory response after traumatic brain injury. Ann Clin Lab Sci 2008; 38: 221-227.

45. Jin W, Wang H, Ji Y, Hu Q, Yan W, Chen G et al. Increased intestinal inflammatory response and gut barrier dysfunction in Nrf2-deficient mice after traumatic brain injury. Cytokine 2008; 44: 135-140

46. Grivennikov S, Karin M. Autocrine IL-6 signaling: a key event in tumorigenesis? Cancer Cell 2008; 13: 7-9.

47. Li C, Lu N, Qi Q, Li F, Ling Y, Chen Y et al. Gambogic acid inhibits tumor cell adhesion by suppressing integrin beta1 and membrane lipid rafts-associated integrin signaling pathway. Biochem Pharmacol 2011; 82: 1873-1883.

48. Yao J, Hu R, Sun J, Lin B, Zhao L, Sha Y et al. Oroxylin A prevents inflammation-related tumor through down-regulation of inflammatory gene expression by inhibiting NF-kappaB signaling. Mol Carcinog 2014; 53: 145-158.

49. Zhao Q, Yang Y, Yu J, You QD, Zeng S, Gu HY et al. Posttranscriptional regulation of the telomerase hTERT by gambogic acid in human gastric carcinoma 823 cells. Cancer Lett 2008; 262: 223-231.

(c) (1) $\odot$ Cell Death and Disease is an open-access journal published by Nature Publishing Group. This work is licensed under a Creative Commons Attribution-NonCommercialNoDerivs 3.0 Unported License. The images or other third party material in this article are included in the article's Creative Commons license, unless indicated otherwise in the credit line; if the material is not included under the Creative Commons license, users will need to obtain permission from the license holder to reproduce the material. To view a copy of this license, visit http://creativecommons.org/ licenses/by-nc-nd/3.0/ 